National Institute of Standards and Technology • U.S. Department of Commerce

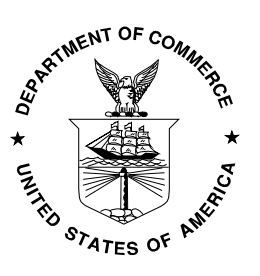

NIST GCR 11-946

NIST NCPDP Analysis - Suitability Assessment

$1^{\text {st }}$ American Systems and Services LLC 
NIST GCR 11-946

\title{
NIST NCPDP Analysis - Suitability Assessment
}

\author{
Prepared for \\ National Institute of Standards and Technology \\ Gaithersburg Md 20899-8202
}

By

$1^{\text {st }}$ American Systems and Services LLC

August 31, 2011

U.S. Department of Commerce John E. Bryson, Secretary

National Institute of Standards and Technology Patrick D. Gallagher, Under Secretary for Standards and Technology and Director

This publication was produced as part of contract SB1341-10-CN-0038 with the National Institute of Standards and Technology. The contents of this publication do not necessarily reflect the views or policies of the National Institute of Standards and Technology or the US Government. 
NIST NCPDP Analysis - Suitability Assessment

Final, August 31, 2011 


\section{Introduction}

This document completes the review of the NCPDP SCRIPT standard by reporting on several aspects related to its suitability as a standard to support Meaningful Use, including:

- completeness, correctness and internal consistency of the standard

- ease of implementability for vendors and other entities building software to support Meaningful Use, including the quality of documentation and other materials associated with the standard

- support for Meaningful Use requirements, including compatibility with other standards named for Meaningful Use.

Portions of this assessment capture insights gained during the creation of a SCRIPT message data set and other analysis performed earlier in this project - for instance as related to SCRIPT's compatibility with other standards and its use of standard terminology - while others are the result of additional review of the standard especially for this document. Below is an overview of the document's contents:

General Quality Assessment. This section reviews the internal consistency, completeness and correctness of the SCRIPT 10.6 XML format from a structural perspective - at a detailed element level. The section assesses the standard section-by-section, calling out specific mechanical issues including isolated errors as well as problems linked to larger implementability challenges described more globally in subsequent parts of this document. Note: The focus of the analysis is the XML format of SCRIPT version 10.6, though the review also considers consistency between the XML and EDIFACT formats of the standard.

SCRIPT and Standard Terminologies. This section focuses on SCRIPT's use of code sets and terminology, assessing the guidance given to implementers on use of terminology in the standard and the compatibility of SCRIPT's terminology use as compared to other standards named for Meaningful use. The section pays special attention to four SCRIPT sections that employ standard terminologies: Medication (including the Structured Sig segment), Observation, Diagnosis and Allergy.

Management of "External Code Lists". This section focuses on issues related to the updating and publishing of NCPDP's External Code List, focusing on impacts to implementers of the SCRIPT 10.6 standard.

Other Implementability. This section identifies other challenges presented by the SCRIPT 10.6 standard from the perspective of the implementer, describing how the components of the standard fit together from an implementer's perspective, assessing strengths and weaknesses and calling out opportunities for improvement. While findings from the quality and terminology reviews factor into this assessment, this section focuses on additional considerations:

- management of changes to the standard and documents related to it, including identification of errors and errata in documentation, capturing of additional guidance in response to implementer questions and experience

- $\quad$ synchronization of XML schema content with the NCPDP External Code List (ECL).

Document References. This section identifies the NCPDP documentation associated with SCRIPT 10.6 and other documents referenced in this assessment.

The findings of this assessment funnel directly into the Standards Action Plan document: this document identifies challenges in the SCRIPT 10.6 standard to be resolved as well as strengths to be built upon, and the Standards Action plan prioritizes those and recommends actions to address them. 
Accordingly, this document focuses on identifying problems and the desirable "improved state" for each, while the Standards Action Plan will suggest how to accomplish those improvements through the NCPDP standards development processes. 


\section{Quality Assessment by SCRIPT Segment}

This section lists quality issues related to the "quality" of the SCRIPT 10.6 standard, in terms of consistency, completeness, and correctness as described below:

- internal consistency within the XML format of the standard (e.g., representing a given concept the same way in different parts of the schema)

- consistency between the SCRIPT 10.6 XML and EDIFACT formats (e.g., ensuring that concepts are represented in an equivalent manner)

- completeness in representing included concepts, for the intended purposes (e.g., the ability to represent the aspects and variations of a concept necessary to meet current industry and regulatory needs), and

- correctness of the SCRIPT 10.6 specification and documentation (e.g., the accuracy of element descriptions, examples, etc.).

This section is organized according to the segments of the standard (high level composites such as "header", "medication", "prescriber").

\section{Header}

The SCRIPT Header contains information used to...

- identify the message sender and recipient

- uniquely identify the message and optionally relate it to an earlier message

- identify the prescription to which the message pertains, both from the prescriber's perspective and the that of the dispensing pharmacy

- state the time the message was sent

- provide security information

- provide mailboxing information if that applies.

The most acute challenges in this section relate to message and prescription references and use of security content. These are described below.

\section{Message and prescription references}

Reliable functioning of medication management workflows depends on accurate references to realworld prescribing and dispensing events, and to related messaging events such as the transmission of the original electronic prescription or an electronic prescription renewal request. Over the course of eprescribing adoption, conventions have arisen in the industry for populating those references in SCRIPT messages, though they were not well-documented in SCRIPT implementation guidance until versions that came after 10.6. Implementers of version 10.6 are provided with vague and inconsistent guidance in this area - causing confusion and leaving guidance up to the multiple prescription networks that route these messages.

As in other cases called out in this assessment, later versions of SCRIPT contain clarifications and guidance that are pertinent to version 10.6, are consistent with current 10.6 industry conventions, and would provide great value to 10.6 implementers. However, this post- 10.6 content is not referenced in any 10.6 implementation materials, leaving implementers to either work from the sometimes incomplete guidance in 10.6 materials or utilize - with uncertainty as to the appropriatenessguidance from later versions of the standard.

Starting with version 10.9, a section entitled Trace Number Usage was included in SCRIPT implementation guides, clarifying use of prescription and message references. Below are excerpts from that section as it appears in a recent version of SCRIPT. 


\subsection{TRACE NUMBER USAGE}

The <MessagelD> and <RelatesToMessagelD> rules are to be followed for assigning, responding, and referencing transaction activity except in the "Mailbox Note" above. Further, the "Transmission Examples" section should be reviewed for implementation and more detail. The following is summary guidelines of the usage.

\begin{tabular}{|l|l|}
\hline Field Name & Remarks \\
\hline <MessagelD & $\begin{array}{l}\text { Unique reference identifier for the transmission, generated from } \\
\text { the sender of the request and the sender of the response. }\end{array}$ \\
\hline <RelatesToMessagelD> & $\begin{array}{l}\text { Specific requirements for long term care. } \\
\text { Is used for linkage to response or to subsequent transactions. }\end{array}$ \\
\hline <RxReferenceNumber> & The prescription number assigned by the pharmacy system. \\
\hline <PrescriberOrderNumber> & The reference number assigned by the prescribing system. \\
\hline
\end{tabular}

In the examples that follow trace and reference numbers are shown to follow through in examples. No intelligence is implied in the values used, or in any sequence.

\subsubsection{EXAMPLE 1}

Prescriber sends the original order, cancels the order, and then sends a new order

\begin{tabular}{|l|l|l|l|}
\hline & NewRx from Prescriber & CancelRx from Prescriber & NewRx from Prescriber \\
\hline Field Name & Value & 1234569 & 1234568 \\
\hline <MessagelD> & 1234567 & 1234567 & \\
\hline <RelatesToMessagelD> & & & \\
\hline <RxReferenceNumber> & & 110088 & 110081 \\
\hline <PrescriberOrderNumber> & 110088 & Status from Pharmacy & Status from Pharmacy \\
\hline & Status from Pharmacy & A66 & A69 \\
\hline <MessagelD> & ABC111 & 1234569 & 1234568 \\
\hline <RelatesToMessagelD> & 1234567 & & \\
\hline <RxReferenceNumber> & & & \\
\hline <PrescriberOrderNumber> & & & \\
\hline
\end{tabular}

[... additional examples provided. Source: 2010121 NCPDP XML Standard Implementation Guide]

The specific elements impacted by this lack of guidance or conflicting guidance in the SCRIPT 10.6 version are detailed below.

\section{MessageID}

EDIFACT: Transaction Control Reference (UIB-030-01)

\section{Implementation Guidance - Errata}

ISSUE: In the UIB element descriptions, the 10.6 Implementation Guide makes specific reference to the STATUS and ERROR messages in the statement: "When $a$ STATUS or ERROR message is generated as a response, the response transaction's Transaction control reference will be echoed back to the sender...”, but this rule applies equally to other response messages (e.g., fill status, renewal request).

RECOMMENDATION: Adjust the statement in the 10.6 IG so that it refers to other response messages in addition to the Status and Error (e.g., fill status, renewal request, change request).

\section{RelatesToMessageID}

EDIFACT: Initiator Reference Identifier OR Dialogue Reference - Initiator Control Reference (UIB-030-02 OR UIH-030-01)

\section{PrescriberOrderNumber}

EDIFACT: Dialogue Reference - Initiator control reference OR Message Reference Number (UIH-030-01 or UIH-020)

\section{RxReferenceNumber}

EDIFACT: Initiator reference identifier OR Message Reference Number (UIB-030-02 or UIH-020) 


\section{Implementation Guidance, Resolve XML/EDIFACT Mapping Conflict}

ISSUE: (1) Implementation guidance on use of trace numbers is unclear in the 10.6 guide and the SCRIPT implementation recommendation document doesn't cover this topic.

(3) The XML indicates that two different EDIFACT elements (UIH-030-01 and UIH020) can both map to the same PrescriberOrderNumber XML concept.

(4) The XML indicates that two different EDIFACT elements (UIB-030-02 and UIH020) can both map to the same RxReferenceNumber XML concept.

(5) The XML indicates that two different EDIFACT elements (UIB-030-02 and UIH030-01) can both map to the same RelatesToMessageID XML concept.

(6) The 10.6 Implementation Guide indicates that Trading Partner-defined usage of these elements is allowed, which can lead to inconsistent implementation.

RECOMMENDATION: (1) Include additional guidance on use of prescriber order IDs, pharmacy prescription IDs and message trace numbers. An appropriate source could be section 9.3 TRACE NUMBER USAGE from the Script v2010121 XML Implementation Guide.

(2) The XML schema relates EDIFACT UIH-020 Message Reference Number, UIH030-01 Dialogue Reference - Initiator control reference and UIB-030-02 Initiator Reference Identifier elements to multiple, overlapping XML elements. Clarify the cases where the XML elements should be mapped to one versus the other.

\section{Security}

The 10.6 implementation materials provide little guidance for use of the Security section of the standard. Generally, additional narrative guidance would be of benefit to implementers. In addition, certain elements in the XML Security composite do not appear to have counterparts in the EDIFACT version of the standard, which could cause challenges for those migrating to the XML format or for those needing to support both formats.

Lastly, the Security composite contains mandatory sub-composites made up solely of optional elements, which could cause questions or challenges for implementers.

Below are particular elements of interest.

\section{Security: UsernameToken \\ EDIFACT: No counterpart}

\section{Implementation Guidance, Resolve XML/EDIFACT Mapping}

ISSUE: This concept does not appear to be present in the EDIFACT format of SCRIPT 10.6. It is unclear whether there is a corollary population of the EDIFACT format. Currently, no guidance is given in the 10.6 IG nor in the most recent SCRIPT or SCRIPT XML IG on use of this composite. 
RECOMMENDATION: Clarify in the 10.6 IG that this composite is available only in the XML format and provide guidance on use of the composite. Reference the SOAP profile if appropriate.

\section{Security: Sender}

EDIFACT: Interchange Sender

Security: Receiver

EDIFACT: Interchange Recipient

\section{XML Schema Challenge, Implementation Guidance}

ISSUE: The SecurityIdentificationType: Sender and SecurityIdentificationType: Receiver composites are mandatory in the 10.6 XML format, but all elements within the composites are optional.

RECOMMENDATION: Modify the XML specification to make these composites optional, or provide clarifying conditionality rules in the Implementation Guide indicating which elements are mandatory in which circumstances.

Other

The mailboxing elements are generally thoroughly documented in the 10.6 materials. However, the documentation omission below was noted during test message creation.

Mailbox: MailboxID

EDIFACT: Interchange Sender: Sender identification

XML Schema Challenge

ISSUE: The XML schema does not include annotations clarifying the mapping of XML concepts to their related EDIFACT elements.

RECOMMENDATION: Add EDIFACT element mapping annotations to the 10.6 XML schema.

\section{Error}

The Error composite is included in multiple SCRIPT message types, and enables a sender to convey aspects of an error situation:

- Code enumerating the high-level category of the error condition

- DescriptionCode providing a more specific error categorization

- Description providing a textual characterization of the error.

One misstatement in the 10.6 Implementation Guide related to this section is described below.

Error: DescriptionCode

EDIFACT: Code List Qualifier (STS-020)

\section{Implementation Guidance}


ISSUE: SCRIPT 10.6 Implementation Guide error: Page 119: STS Status segment usage table shows Not Used for this element in Verify, but includes confusing content in the Remarks, apparently copied from the Status Type, Coded remarks:

"Is not required in a VERIFY transaction. If used, Status Type (Ø1Ø/9Ø15) must be ØØØ and Reject Codes (Ø2Ø/1131) may not be used. Free Text (Ø3Ø/444Ø) may be used."

RECOMMENDATION: Remove or correct the erroneous statement above in the 10.6 implementation guide, Page 119: STS Status segment usage table.

\section{Request}

The Request composite, included in multiple SCRIPT message types, is used to convey information clarifying the nature or specifics of the particular request.

As is the case for many SCRIPT elements, the allowed values for one Request element, ChangeRequestType, are maintained in the NCPDP External Code List document. However, this element is impacted by ECL editing conventions that make finding the current, allowed values problematic. Background on this challenge is provided in contained in the Management of "External Code Lists" section later in this document. Details on the impacted Request elements are below.

\section{Request: ChangeRequestType}

EDIFACT: Message Function, Coded (REQ-010)

\section{Implementation Guidance, SCRIPT Enhancement Opportunity}

ISSUE: The 10.6 concept associated with this element (4343 Message Function, Coded) is not present in the current ECL version. Instead, the concept that replaced it in later SCRIPT versions-MessageRequestCode-is present, with direction to "See 4343 Message Function, coded for SCRIPT Versions $1 \varnothing .11$ and lower". The lack of this concept in recent ECL versions conflicts with guidance in the Standards Matrix document which indicates the "most recent" ECL may be used with 10.6. Implementers desiring to use the most recent ECL but implementing RxChange, Census, or the LTPAC prescription change process must also use an older ECL version containing the missing 4343 Message Function, Coded concept.

RECOMMENDATION: Include all version 10.6 ECL concepts in current ECL document versions. This will enable an implementer to use a single ECL version rather than needing to "mix and match" versions in order to cover all 10.6 concepts. This will also reduce confusion for implementers who reasonably expect the current ECL version to cover all concepts included in the most recent SCRIPT version in use in the industry and named in federal regulation. See the section elsewhere in this document entitled Handling of concept changes with respect to actively-implemented standards.

\section{Response}


As is the case for a number of SCRIPT elements, shared ECL code sets support Request segment elements which are used in multiple SCRIPT message types. The result is that certain values available for use in these elements that are inappropriate in certain messages. In addition, the ApprovedWithChanges sub-composite is allowed in a message type where it is inappropriate. Details are below.

\section{Response: Approved: ApprovalReasonCode EDIFACT: Code List Qualifier (RES-020)}

Response: Denied: DenialReasonCode

EDIFACT: Code List Qualifier (RES-020)

Response: DeniedNewPrescriptionToFollow: DenialReasonCode EDIFACT: Code List Qualifier (RES-020)

\section{XML Schema Challenge, Implementation Guidance, SCRIPT Enhancement Opportunity}

ISSUE: Not all codes allowed for these elements are appropriate in all message types or composites.

(See the section elsewhere in this document entitled Consolidation of terms and values from dissimilar standards for additional background)

RECOMMENDATION: In the ECL, in cases where not all values for a concept are applicable in all composite / element instances where it appears, provide a separate set of code values for each instance containing only the applicable values. Update the XML schema accordingly.

\section{Response: ApprovedWithChanges \\ EDIFACT: Response Type, Coded (RES-010) \\ Implementation Guidance, SCRIPT Enhancement Opportunity}

ISSUE: "ApprovedWithChanges" is allowed as a response to a Cancel request, but that does not reflect a meaningful real-world scenario.

RECOMMENDATION: Add clarification in the 10.6 implementation guide (through Errata or other means) that ApprovedWithChanges is not an appropriate response to a Cancel request. Adjust or remove this option in later SCRIPT versions.

\section{Pharmacy}

The Pharmacy composite is used to convey information about a sending or receiving pharmacy, including address and key industry identifiers.

\section{Identifiers}

Below are challenges and opportunities related to pharmacy identifier elements in the SCRIPT standard.

\section{Pharmacy: Identification}

EDIFACT: Reference Number (PVD-020) 
There are several cases where there is a mismatch between the number of allowed Identification instances allowed in the EDIFACT format versus the number allowed in the XML schema, including this element. See the section, XML element cardinality issues, elsewhere in this document for details.

\section{Pharmacy: Identification}

EDIFACT: Reference Number (PVD-020-01 (value), PVD-020-02 (qualifier))

The Identification concept is used to convey identifiers for pharmacies, prescribers, facilities and patients. Because the associated ECL concept contains identifier types to support all these entities, only a subset are appropriate for each element, and the remainder are inappropriate. See the section, ECL concept mixes identifier types, elsewhere in this document for details.

\section{Pharmacy: Identification}

EDIFACT: Reference Number (PVD-020-01 (value), PVD-020-02 (qualifier))

The Identification concept does not enable differentiation between Individual and Organizational NPIs and DEA Numbers, and DEA suffixes are not explicitly supported. See the section, No differentiation between Individual and Organizational NPI and DEA, elsewhere in this document for details.

\section{Pharmacy: Identification: StateLicenseNumber}

EDIFACT: Reference Number (PVD-020-01 (value), PVD-020-02 value: "0B" (qualifier))

The Identification concept does not include a state qualifier element for use with State License Numbers or DEA Numbers - which may be needed when an entity is licensed or registered in more than one state. See the section, Lacking state qualifiers for certain identifiers, elsewhere in this document for details.

\section{Address}

Pharmacy: Address: AddressLine2

EDIFACT: Place / Location (PVD-080-06)

Pharmacy: Address: PlaceLocationQualifier

EDIFACT: Place / Location Qualifier (PVD-080-05)

The same challenges and opportunities affecting the AddressLine 2 and

PlaceLocationQualifier address elements throughout the SCRIPT standard affect these elements. See the section, Challenges impacting SCRIPT elements in multiple segments, elsewhere in this document for details. 


\section{Prescriber}

The Prescriber composite is used to convey information about a sending or receiving prescriber, including address and key industry identifiers.

\section{XML representation in the Medication History Response}

\section{Prescriber}

PVD Segment

\section{Implementation Guidance, XML Schema Challenge}

ISSUE: In the Medication History Response, the Prescriber composite prior to the medication history loops is mandatory; however, every element within the Prescriber composite is optional. As a result, an empty composite (<Prescriber $><$ /Prescriber $>$ ) is sufficient.

RECOMMENDATION: Clarify the intent for population of the Prescriber composite in the main section of the medication history response message. Provide the related guidance for use of the element in the 10.6 Implementation Guide.

\section{Identifiers}

Below are challenges and opportunities related to prescriber identifier elements in the SCRIPT standard.

\section{Prescriber: Identification}

EDIFACT: Reference Number (PVD-020)

There are several cases where there is a mismatch between the number of allowed Identification instances allowed in the EDIFACT format versus the number allowed in the XML schema, including this element. See the section, XML element cardinality issues, elsewhere in this document for details.

\section{Prescriber: Identification \\ EDIFACT: Reference Number (PVD-020-01 (value), PVD-020-02 (qualifier))}

The Identification concept is used to convey identifiers for pharmacies, prescribers, facilities and patients. Because the associated ECL concept contains identifier types to support all these entities, only a subset are appropriate for each element, and the remainder are inappropriate. See the section, ECL concept mixes identifier types, elsewhere in this document for details.

\section{Prescriber: Identification}

EDIFACT: Reference Number (PVD-020-01 (value), PVD-020-02 (qualifier))

The Identification concept does not enable differentiation between Individual and Organizational NPIs and DEA Numbers, and DEA suffixes are not explicitly supported. See the section, No differentiation between Individual and Organizational NPI and DEA, elsewhere in this document for details. 


\section{Prescriber: Identification: DEANumber}

EDIFACT: Reference Number (PVD-020-01 (value), PVD-020-02 value: "DH" (qualifier))

Prescriber: Identification: StateLicenseNumber

EDIFACT: Reference Number (PVD-020-01 (value), PVD-020-02 value: "OB" (qualifier))

The Identification concept does not include a state qualifier element for use with State License Numbers or DEA Numbers - which may be needed when an entity is licensed or registered in more than one state. See the section, Lacking state qualifiers for certain identifiers, elsewhere in this document for details.

\section{Address}

\section{Prescriber: Address: AddressLine2}

EDIFACT: Place / Location (PVD-080-06)

Prescriber: Address: PlaceLocationQualifier

EDIFACT: Place / Location Qualifier (PVD-080-05)

The same challenges and opportunities affecting the AddressLine2 and PlaceLocationQualifier address elements throughout the SCRIPT standard affect these elements. See the section, Challenges impacting SCRIPT elements in multiple segments, elsewhere in this document for details.

\section{Supervisor}

The optional Supervisor segment contains the same elements as the Prescriber composite, but represents a supervising clinician.

\section{Supervisor: Identification}

EDIFACT: Reference Number (PVD-020)

There are several cases where there is a mismatch between the number of allowed Identification instances allowed in the EDIFACT format versus the number allowed in the XML schema, including this element. See the section, XML element cardinality issues, elsewhere in this document for details.

\section{Supervisor: Identification \\ EDIFACT: Reference Number (PVD-020-01 (value), PVD-020-02 (qualifier))}

The Identification concept is used to convey identifiers for pharmacies, prescribers, facilities and patients. Because the associated ECL concept contains identifier types to support all these entities, only a subset are appropriate for each element, and the remainder are inappropriate. See the section, ECL concept mixes identifier types, elsewhere in this document for details.

\section{Supervisor: Identification}

EDIFACT: Reference Number (PVD-020-01 (value), PVD-020-02 (qualifier)) 
The Identification concept does not enable differentiation between Individual and Organizational NPIs and DEA Numbers, and DEA suffixes are not explicitly supported. See the section, No differentiation between Individual and Organizational NPI and DEA, elsewhere in this document for details.

\section{Supervisor: Identification: DEANumber}

EDIFACT: Reference Number (PVD-020-01 (value), PVD-020-02 value: "DH" (qualifier))

Supervisor: Identification: StateLicenseNumber

EDIFACT: Reference Number (PVD-020-01 (value), PVD-020-02 value: "0B" (qualifier))

The Identification concept does not include a state qualifier element for use with State License Numbers or DEA Numbers - which may be needed when an entity is licensed or registered in more than one state. See the section, Lacking state qualifiers for certain identifiers, elsewhere in this document for details.

\section{Address}

Supervisor: Address: AddressLine2

EDIFACT: Place / Location (PVD-080-06)

Supervisor: Address: PlaceLocationQualifier

EDIFACT: Place / Location Qualifier (PVD-080-05)

The same challenges and opportunities affecting the AddressLine 2 and PlaceLocationQualifier address elements throughout the SCRIPT standard affect these elements. See the section, Challenges impacting SCRIPT elements in multiple segments, elsewhere in this document for details.

\section{Facility}

The Facility composite is used to convey information about a sending or receiving long-term or postacute care facility, including address and key industry identifiers.

\section{Identifiers}

Below are challenges and opportunities related to pharmacy identifier elements in the SCRIPT standard.

\section{Facility: Identification}

EDIFACT: Reference Number (PVD-020)

There are several cases where there is a mismatch between the number of allowed Identification instances allowed in the EDIFACT format versus the number allowed in the XML schema, including this element. See the section, XML element cardinality issues, elsewhere in this document for details.

\section{Facility: Identification: NPI}

EDIFACT: Reference Number (PVD-020-01 (value), PVD-020-02 value: "HPI" (qualifier))

The Identification concept is used to convey identifiers for pharmacies, prescribers, facilities and patients. Because the associated ECL concept contains identifier types to support all these 
entities, only a subset are appropriate for each element, and the remainder are inappropriate. See the section, ECL concept mixes identifier types, elsewhere in this document for details.

\section{Facility: Identification: NPI}

EDIFACT: Reference Number (PVD-020-01 (value), PVD-020-02 value: "HPI" (qualifier))

The Identification concept does not enable differentiation between Individual and Organizational NPIs and DEA Numbers, and DEA suffixes are not explicitly supported. See the section, No differentiation between Individual and Organizational NPI and DEA, elsewhere in this document for details.

\section{Facility: Identification: StateLicenseNumber}

EDIFACT: Reference Number (PVD-020-01 (value), PVD-020-02 value: "0B" (qualifier))

The Identification concept does not include a state qualifier element for use with State License Numbers or DEA Numbers - which may be needed when an entity is licensed or registered in more than one state. See the section, Lacking state qualifiers for certain identifiers, elsewhere in this document for details.

\section{Facility name}

Facility: FacilityName

EDIFACT: Party Name (PVD-070)

\section{SCRIPT Enhancement Opportunity}

ISSUE: The facility name is not a required element, which is inconsistent with other similar concepts (pharmacy, prescriber).

RECOMMENDATION: Consider making the facility name element mandatory in future SCRIPT releases, to ensure adequate identification of the sending or receiving facility.

\section{Address}

Facility: Address

EDIFACT: Address (PVD-080)

\section{SCRIPT Enhancement Opportunity}

ISSUE: The facility address is not a required composite for any message type, which is inconsistent with other similar concepts (pharmacy, prescriber). 
RECOMMENDATION: Consider making the facility address composite mandatory in appropriate message types in future SCRIPT releases, to ensure adequate identification of the sending or receiving facility.

\section{Facility: Address: AddressLine2}

EDIFACT: Place / Location (PVD-080-06)

Facility: Address: PlaceLocationQualifier

EDIFACT: Place / Location Qualifier (PVD-080-05)

The same challenges and opportunities affecting the AddressLine 2 and PlaceLocationQualifier address elements throughout the SCRIPT standard affect these elements. See the section, Challenges impacting SCRIPT elements in multiple segments, elsewhere in this document for details.

\section{Patient}

The Patient composite is used to convey information about the patient who is the subject of the SCRIPT message. Information typically populated in the Patient segment includes patient name, date of birth, address and telephone numbers. Below are challenges related to patient information in the 10.6 standard.

\section{Identification}

\section{Patient: Identification}

EDIFACT: Reference Number (PTT-050)

\section{XML Schema Challenge, Implementation Guidance, SCRIPT Enhancement Opportunity}

ISSUE: The location of the patient identification composite is different in the XML format of the Medication History and Verify messages than in all other SCRIPT messages.

RECOMMENDATION: Note the different element sequence for Medication History and Verify messages in the 10.6 Implementation Guide, and consider making the sequence consistent in future SCRIPT versions.

\section{Patient: Identification}

EDIFACT: Reference Number (PTT-050)

There are several cases where there is a mismatch between the number of allowed Identification instances allowed in the EDIFACT format versus the number allowed in the XML schema, including this element. See the section, XML element cardinality issues, elsewhere in this document for details.

\section{Patient: Identification}

EDIFACT: Reference Number (PTT-050-01 (value), PTT-050-02 (qualifier)) 
The Identification concept is used to convey identifiers for pharmacies, prescribers, facilities and patients. Because the associated ECL concept contains identifier types to support all these entities, only a subset are appropriate for each element, and the remainder are inappropriate. See the section, ECL concept mixes identifier types, elsewhere in this document for details.

\section{Date of birth}

\section{Patient: DateOfBirth OR DateTime EDIFACT: Century Date (PTT-020)}

\section{XML Schema Challenge, Implementation Guidance, SCRIPT Enhancement Opportunity}

ISSUE: The location of Patient Date of Birth is different in the XML format of the Medication History and Verify messages than in all other SCRIPT messages.

RECOMMENDATION: Note the different element sequence for Medication History and Verify messages in the 10.6 Implementation Guide, and consider making the sequence consistent in future SCRIPT versions.

\section{Patient: DateOfBirth OR DateTime}

EDIFACT: Century Date (PTT-020)

\section{Implementation Guidance, XML Schema Challenge}

ISSUE: The XML schema supports a date/time representation of the Date of Birth, in contrast to the EDIFACT format in which the Date of Birth format is CCYYMMDD. It is questionable whether the time portion is useful / meaningful in the DateOfBirth element.

RECOMMENDATION: Add guidance to the 10.6 Implementation Guide describing the cases where the time format is appropriate for DateOfBirth (if any). Adjust the XML schema to remove the date/time aspect of patient date of birth.

Address

Patient: Address: AddressLine2

EDIFACT: Place / Location (PVD-080-06)

Patient: Address: PlaceLocationQualifier

EDIFACT: Place / Location Qualifier (PTT-060-05)

The same challenges and opportunities affecting the AddressLine2 and PlaceLocationQualifier address elements throughout the SCRIPT standard affect these elements. See the section, Challenges impacting SCRIPT elements in multiple segments, elsewhere in this document for details.

\section{Other patient information}

\section{Patient: PatientRelationship}

EDIFACT: Individual Relationship, Coded (PTT-010) 


\section{Implementation Guidance}

ISSUE: It is unclear what the anticipated and appropriate use of this element is in most prescription messages (presumably this information could be pertinent in a medication history request directed to the patient's payer).

RECOMMENDATION: Add guidance to the 10.6 Implementation Guide describing the expected use of this element. Potentially limit use to the message(s) in which cardhholder relationship is appropriate.

\section{Medication}

The Medication composite has three variations... for conveying a prescribed, dispensed, or requested medication.

Medication composite in the Refill Response

\section{Medication : MedicationPrescribed | MedicationDispensed \\ In the Refill Response Message \\ EDIFACT: DRU segment}

\section{XML Schema Challenge, Implementation Guidance}

ISSUE: In the Refill Response, the Implementation Guide indicates that the Medication / DRU is optional... neither prescribed nor dispensed medication is required. But the XML schema requires a prescribed medication.

RECOMMENDATION: Clarify whether the standard intends for a prescribed medication to be required in the Refill Response message. Adjust the 10.6 Implementation Guide or XML schema based on that determination.

\section{Coded Medication}

\section{Medication : DrugCoded: ProductCodeQualifier}

EDIFACT: Code List Responsibility Agency (DRU-010-04)

\section{XML Schema Challenge, Implementation Guidance, SCRIPT Enhancement Opportunity}

ISSUE: Not all code sets would be appropriate in a new prescription or other given message type. For example, the standard does not anticipate that a prescription would be created for a drug class (NDF-RT) or ingredient (UNII).

RECOMMENDATION: In the ECL, in cases where not all values for a concept are applicable in all composite / element instances where it appears, provide a separate set of code values for each instance containing only the applicable values. Update the XML schema accordingly.

Potentially include direction in the Implementation Guide in addition to or in place of ECL changes. 


\section{Medication : DrugCoded: DrugDBCodeQualifier}

EDIFACT: Reference Qualifier (DRU-010-09)

\section{Implementation Guidance, SCRIPT Enhancement Opportunity}

ISSUE: The 10.6 schema at the outset of this analysis did not include the RxNorm qualifiers required by Meaningful Use for new prescriptions (BPK, GPK, SCD, SBD). These terminologies have been present in the ECL since June 2010, but the 10.6 schema included only the ECL content present in the October 2008 ECL document.

After notification of NCPDP, an the schema was updated with the additional RxNorm qualifiers and republished. However, the current published 10.6 schema still reflects the October 2010 ECL for most concepts, with content from newer ECL versions only for certain concepts--where requested by members.

RECOMMENDATION: See the sections, Management of "External Code Lists" and ECL Version Management and the XML Schema, below

\section{Directions}

\section{Medication : Directions}

EDIFACT: Directions (DRU-030-02 and 03)

\section{SCRIPT Enhancement Opportunity}

ISSUE: The maximum length of this element is insufficient for certain situations, e.g., where dosing is based on a clinical reading and a number of different variations must be provided.

RECOMMENDATION: Expand the element to accommodate all direction scenarios.

\section{Quantity / Refills}

Medication : Refills: Qualifier

In the Refill Request Message

EDIFACT: Quantity Qualifier (DRU-060-01)

\section{XML Schema Challenge, Implementation Guidance}

ISSUE: In the Refill Request message, prescribed drug loop, the schema does not allow the "R" (original number of refills) value, in conflict with the Implementation Guide specification and example. This appears to be an error in the XML schema.

RECOMMENDATION: Confirm the omission of the Quantity: Qualifier "R" value in the Refill Request's prescribed medication loop. If the intent was to allow the "R" value, correct the schema accordingly. 
Medication-related date and time elements

In the following elements, a time component is supported in the XML format, whereas it would not be included in the EDIFACT format. Additional guidance would be valuable to assist implementers in the appropriate population of the date/time elements.

Medication : WrittenDate: OR DateTime

EDIFACT: Date/Time Period Qualifier, Date/Time Period, Date/Time Period Format Qualifier (DRU-040-01 (date type=85), DRU-040-02 (value), DRU-040-03 (format))

Medication : LastFillDate: OR DateTime

EDIFACT: Date/Time Period Qualifier, Date/Time Period, Date/Time Period Format Qualifier (DRU-040-01 (date type =LD), DRU-040-02 (value), DRU-040-03 (format))

Medication : ExpirationDate: OR DateTime

EDIFACT: Date/Time Period Qualifier, Date/Time Period, Date/Time Period Format Qualifier (DRU-040-01 (date type=36), DRU-040-02 (value), DRU-040-03 (format))

Medication : EffectiveDate: OR DateTime

EDIFACT: Date/Time Period Qualifier, Date/Time Period, Date/Time Period Format Qualifier (DRU-040-01 (date type=07), DRU-040-02 (value), DRU-040-03 (format))

Medication : PeriodEnd: OR DateTime

EDIFACT: Date/Ti-me Period Qualifier, Date/Time Period, Date/Time Period Format Qualifier (DRU-040-01 (date type=PE), DRU-040-02 (value), DRU-040-03 (format))

Medication : DeliveredOnDate: OR DateTime

EDIFACT: Date/Time Period Qualifier, Date/Time Period, Date/Time Period Format Qualifier (DRU-040-01 (date type=35), DRU-040-02 (value), DRU-040-03 (format))

Medication : DateValidated: OR DateTime

EDIFACT: Date/Time Period Qualifier, Date/Time Period, Date/Time Period Format Qualifier

(DRU-040-01 (date type=BE), DRU-040-02 (value), DRU-040-03 (format))

Medication : SoldDate: OR DateTime

EDIFACT: Date/Time Period Qualifier, Date/Time Period, Date/Time Period Format Qualifier

(DRU-040-01 (date type=06), DRU-040-02 (value), DRU-040-03 (format))

\section{Implementation Guidance}

ISSUE: No direction is given regarding whether and when it is necessary to include the time portion when communicating this date.

RECOMMENDATION: Provide guidance on the use of DateTime versus Date types for each of SCRIPT's date elements.

\section{Medication : DeliveredOnDate: Date}

EDIFACT: Date/Time Period Qualifier, Date/Time Period, Date/Time Period Format Qualifier

(DRU-040-01 (date type=35), DRU-040-02 (value), DRU-040-03 (format))

\section{XML Schema Challenge}

ISSUE: The XML schema allows a DeliveredOnDate in the New Prescription message; however, this element is only used in the Fill Status and subsequent messages in long-term and post-acute settings to indicate the date on which the medication was delivered to the facility. 
RECOMMENDATION: Remove the DeliveredOnDate element from the NewRx message XML schema.

\section{Diagnosis in the Medication composite}

Medication : Diagnosis: Qualifier

EDIFACT: Code List Qualifier (DRU-070-03)

\section{Implementation Guidance, ECL Challenge}

ISSUE: The diagnosis qualifier (ICD-9, ICD-10, etc.) is optional in both the Implementation Guide and schema, with no conditionality stated. It would be appropriate to require the Diagnosis: Qualifier element when the Diagnosis: Value element is populated. If not populated, the receiving system may not be able to use the coded diagnosis content.

RECOMMENDATION: (1) Provide guidance in the Implementation Guide recommending that the Diagnosis: Qualifier to be populated when the corresponding Value element is populated.

(2) Consider adjusting the standard to require the Qualifier in such cases.

\section{Medication : Diagnosis: Qualifier}

EDIFACT: Code List Qualifier (DRU-070-05)

\section{XML Schema Challenge, Implementation Guidance, ECL Challenge}

ISSUE: (1) See note on Diagnosis: Primary: Qualifier

(2) Incorrect annotation in the XML schema: The current annotation indicates that this XML element relates to EDIFACT DRU-070-04. Instead, should reference DRU-070-05.

RECOMMENDATION: (1) See note on Diagnosis: Primary: Qualifier.

(2) Correct the annotation in the XML schema so that it relates this XML element to EDIFACT DRU-070-05.

\section{Medication : Diagnosis: Value}

EDIFACT: Clinical Information - Secondary (DRU-070-04)

\section{XML Schema Challenge, Implementation Guidance}

ISSUE: (1) This element is specified as optional in the XML schema, but given the XML structure, including Secondary Diagnosis without a code value would result in an effectively "empty" composite. 
(2) Incorrect annotation in the XML schema: The current annotation indicates that this XML element relates to EDIFACT DRU-070-05. Instead, should reference DRU- 070-04.

RECOMMENDATION: (1) Adjust the XML schema to make the Diagnosis: Secondary: Value element mandatory.

(2) Correct the annotation in the XML schema so that it relates this XML element to EDIFACT DRU-070-04

\section{Prior Authorization}

\section{Medication : PriorAuthorization : Qualifier}

EDIFACT: Reference Qualifier (DRU-080-02)

\section{XML Schema Challenge, Implementation Guidance, SCRIPT Enhancement Opportunity}

ISSUE: The External Code List values for this element range from State License Number (0B) to BIN Location Number (BO), in addition to Prior Authorization Number (G1) and "order number" (94 - Pharmacy or Prescriber File ID)

RECOMMENDATION: In the ECL, in cases where not all values for a concept are applicable in all composite / element instances where it appears, provide a separate set of code values for each instance containing only the applicable values. (In this case, only G1/PA Number and 94/Order Number are valid). Update the XML schema accordingly

Potentially include direction in the Implementation Guide in addition to or in place of ECL changes

\section{Medication : PriorAuthorization : Value}

EDIFACT: Reference Number (DRU-080-01)

\section{Implementation Guidance, ECL Challenge}

ISSUE: This element has two usages as described in the Implementation Guide--conveying prescription order numbers in the Medication History response message and communicating a prior authorization number in other messages. The XML element naming is not reflective of the two uses.

RECOMMENDATION: Consider changing the name for this element in the XML to more accurately reflect the stated usages (including stating the order number in Medication History messages), or potentially adding an element dedicated to each purpose.

Dispensing Pharmacy (Medication History only)

Pharmacy (Med History): Identification

EDIFACT: Reference Number (PVD-020) 
There are several cases where there is a mismatch between the number of allowed Identification instances allowed in the EDIFACT format versus the number allowed in the XML schema, including this element. See the section, XML element cardinality issues, elsewhere in this document for details.

\section{Pharmacy (Med History): Identification}

EDIFACT: Reference Number (PVD-020)

The Identification concept is used to convey identifiers for pharmacies, prescribers, facilities and patients. Because the associated ECL concept contains identifier types to support all these entities, only a subset are appropriate for each element, and the remainder are inappropriate. See the section, ECL concept mixes identifier types, elsewhere in this document for details.

\section{Pharmacy (Med History): Identification: StateLicenseNumber}

EDIFACT: Reference Number (PVD-020-01 (value), PVD-020-02 value: "0B" (qualifier))

The Identification concept does not include a state qualifier element for use with State License Numbers or DEA Numbers - which may be needed when an entity is licensed or registered in more than one state. See the section, Lacking state qualifiers for certain identifiers, elsewhere in this document for details.

\section{Pharmacy (Med History): Address: AddressLine2}

EDIFACT: Place / Location (PVD-080-06)

\section{Pharmacy (Med History): Address: PlaceLocationQualifier}

EDIFACT: Place / Location Qualifier (PVD-080-05)

The same challenges and opportunities affecting the AddressLine2 and

PlaceLocationQualifier address elements throughout the SCRIPT standard affect the elements below. See the section, Challenges impacting SCRIPT elements in multiple segments, elsewhere in this document for details.

\section{Ordering Prescriber (Medication History only)}

\section{Prescriber (Med History): Identification}

EDIFACT: Reference Number (PVD-020)

There are several cases where there is a mismatch between the number of allowed Identification instances allowed in the EDIFACT format versus the number allowed in the XML schema, including this element. See the section, XML element cardinality issues, elsewhere in this document for details.

\section{Prescriber (Med History): Identification}

EDIFACT: Reference Number (PVD-020) 
The Identification concept is used to convey identifiers for pharmacies, prescribers, facilities and patients. Because the associated ECL concept contains identifier types to support all these entities, only a subset are appropriate for each element, and the remainder are inappropriate. See the section, ECL concept mixes identifier types, elsewhere in this document for details.

\section{Prescriber (Med History): Identification: StateLicenseNumber}

EDIFACT: Reference Number (PVD-020-01 (value), PVD-020-02 value: "0B" (qualifier))

The Identification concept does not include a state qualifier element for use with State License Numbers or DEA Numbers - which may be needed when an entity is licensed or registered in more than one state. See the section, Lacking state qualifiers for certain identifiers, elsewhere in this document for details.

\section{Prescriber (Med History): Address: AddressLine2}

EDIFACT: Place / Location (PVD-080-06)

Prescriber (Med History): Address: PlaceLocationQualifier

EDIFACT: Place / Location Qualifier (PVD-080-05)

The same challenges and opportunities affecting the AddressLine2 and

PlaceLocationQualifier address elements throughout the SCRIPT standard affect the elements below. See the section, Challenges impacting SCRIPT elements in multiple segments, elsewhere in this document for details.

\section{Drug Use Evaluation}

\section{DrugUseEvaluation: CoAgentQualifier}

EDIFACT: DUE Co-Agent ID Qualifier (DRU-100-05)

\section{SCRIPT Enhancement Opportunity, ECL Challenge}

ISSUE: The list of DUE co-agent qualifiers associated with this element does not include NDF-RT, for drug class.

RECOMMENDATION: Consider adding drug class / NDF-RT to the list of allowed co-agent qualifiers in the External Code List

\section{Drug coverage status}

\section{DrugCoverageStatusCode}

EDIFACT: Drug Coverage Status Code (DRU-110)

\section{Implementation Guidance, ECL Challenge}

ISSUE: Usage rules for non-DEA controlled substance products is not clear. 
RECOMMENDATION: Provide additional guidance on the use of the DrugCoverageStatusCode for cases where the prescribed medication is not a controlled substance. Consider discontinuing use of the field for non-controlled substance prescriptions if adoption of the element has not occurred.

\section{Delivery time requested}

\section{NeededNoLaterThan: TimeZone: Time Zone}

EDIFACT: Time Zone (DRU-150)

\section{ECL Challenge}

ISSUE: This element is only to be used with the NeededNoLaterThan element.

RECOMMENDATION: Consider combining the NeededNoLaterThan date with the TimeZone and NeededNoLaterThanReason into a single composite of related elements

\section{NeededNoLatherThanReason}

EDIFACT: Needed No Later Than Reason (DRU-160)

\section{ECL Challenge}

ISSUE: This element is only to be used with the NeededNoLaterThan element.

RECOMMENDATION: Consider combining the NeededNoLaterThan date with the TimeZone and NeededNoLaterThanReason into a single composite of related elements.

\section{Structured Sig}

The Structured Sig segment breaks out the components of a prescription's administration directions, optionally codifying these aspects using standard terminologies.

In SCRIPT version 10.6, much of the content in the segment is optional, and direction regarding its use in the 10.6 Implementation Guide is light; a separate Structured Sig Implementation Guide is published by NCPDP, but is not explicitly referenced in the 10.6 SCRIPT IG or other guidance materials. Further, guidance as to the use of terminologies differs to some extent between the SCRIPT 10.6 and Structured Sig Implementation Guides - in particular, the SCRIPT 10.6 guide allows use of Federal Medication Terminologies (FMT) in nearly all coded elements, but the Structured Sig guide limits use of FMT to one composite.

In addition, the reference to FMT is itself very imprecise, in that there are several terminologies within FMT, including several subsets.

This section identifies inconsistencies in guidance between the SCRIPT 10.6 and Structured Sig Implementation Guides that will likely cause challenges for implementers, as well as other documentation points to be addressed. 
Use of standard terminologies in SCRIPT is discussed further in SCRIPT and Standard Terminologies later in this document.

\section{StructuredSig}

EDIFACT: Structured Sig segment elements

\section{XML Schema Challenge, Implementation Guidance, SCRIPT Enhancement Opportunity}

ISSUE: The SCRIPT 10.6 Implementation Guide and the Structured Sig v1.1 Implementation Guide are inconsistent with respect to the terminology allowed in the Sig segment. The 10.6 IG and associated ECL allow both FMT and SNOMED CT concepts in nearly all Sig elements, whereas the Structured Sig v1.1 IG recommends that FMT only be used in one element.

Elements for which the Structured Sig v1.1 IG directs use of SNOMED only, in conflict with the 10.6 XML schema, IG and ECL which allow both FMT and SNOMED:

StructuredSig: RouteOfAdministration: RouteofAdministrationCodeQualifier EDIFACT: Route of Administration Code Qualifier (SIG-070-02)

\section{StructuredSig: SiteofAdministration: SiteofAdministrationCodeQualifier} EDIFACT: Site of Administration Code Qualifier (SIG-080-02)

StructuredSig: Timing: AdministrationTimingCodeQualifier EDIFACT: Administration Timing Code Qualifier (SIG-090-02)

StructuredSig: Timing: RateUnitofMeasureCodeQualifier EDIFACT: Rate Unit of Measure Code Qualifier (SIG-090-07)

StructuredSig: Timing: TimePeriodBasisCodeQualifier EDIFACT: Time Period Basis Code Qualifier (SIG-090-10)

StructuredSig: Timing: IntervalUnitsCodeQualifier EDIFACT: Interval Units Code Qualifier (SIG-090-19)

StructuredSig: Duration: DurationTextCodeQualifier EDIFACT: Duration Text Code Qualifier (SIG-100-03)

StructuredSig: MaximumDoseRestriction: MaximumDoseRestrictionCodeQualifier

EDIFACT: Maximum Dose Restriction Code Qualifier (SIG-110-03)

StructuredSig: MaximumDoseRestriction: MaximumDoseRestrictionVariableUnitsCodeQualifier EDIFACT: Maximum Dose Restriction Variable Units Code Qualifier (SIG-110-07)

StructuredSig: Indication: IndicationPrecursorCodeQualifier EDIFACT: Indication Precursor Code Qualifier (SIG-120-02)

\section{StructuredSig: Indication: IndicationTextCodeQualifier}


EDIFACT: Indication Text Code Qualifier (SIG-120-05)

StructuredSig: Indication: IndicationValueUnitofMeasureCodeQualifier

EDIFACT: Indication Value Unit of Measure Code Qualifier (SIG-120-10)

StructuredSig: Dose: DoseDeliveryMethodCodeQualifier

EDIFACT: Dose Delivery Method Code Qualifier (SIG-040-03)

StructuredSig: Dose: DoseDeliveryMethodModifierCodeQualifier

EDIFACT: Dose Delivery Method Modifier Code Qualifier (SIG-040-06)

RECOMMENDATION: (1) Provide consistent guidance between the SCRIPT 10.6 and Structured Sig 1.1 Implementation Guides and ECL for terminologies to be used in Sig segment elements. Update the associated XML schema valid values to match the consistent guidance.

(2) Clarify for implementers how the Structured Sig v1.1 IG should or shouldn't be used in the development of SCRIPT 10.6 support. (Current SCRIPT 10.6 IG, Implementation

Recommendations and Read Me documents do not reference the Structured Sig 1.1 IG).

\section{StructuredSig: CodeSystem: FMTVersion}

EDIFACT: FMT Version (SIG-020-02)

\section{Implementation Guidance, SCRIPT Enhancement Opportunity}

ISSUE: There are several FMT terminologies that are allowed to be used in the Structured Sig segment, not all contained in the NCI NCPDP subset (e.g., route of administration), and not all are updated on the same schedule. An implementer that uses multiple FMT terminologies may need to set this value to a date that reflects one but not all FMT terminologies used.

RECOMMENDATION: (1) Provide guidance in the 10.6 Implementation Guide or addendum regarding population of this element when multiple FMT terminologies are used by the implementer.

(2) Consider limiting the use of FMT to the one concept recommended for FMT in the Structured Sig 1.1 Implementation Guide, which would help to clarify expected terminology use for implementers, and would also avoid the need to choose between FMT version dates when populating this element.

\section{StructuredSig: FreeText: SigFreeText}

EDIFACT: Directions (SIG-030-02)

\section{SCRIPT Enhancement Opportunity}

ISSUE: The maximum length of this element is insufficient for certain situations, e.g., where dosing is based on a clinical reading and a number of different variations must be provided. 
RECOMMENDATION: Expand the element to accommodate all direction scenarios.

\section{StructuredSig: FreeText: SigFreeText}

EDIFACT: Sig Free Text (SIG-030-02)

\section{Implementation Guidance - Errata}

ISSUE: An example in the 10.6 implementation guide (12.31.4 Tapered dose, page 367) contains two errors in this element: (1) it exceeds the maximum length of 140 characters for this element, and (2) it omits the value in loops after the initial SIG loop.

RECOMMENDATION: Correct the SCRIPT 10.6 Implementation Guide example or provide the correction in an addendum.

\section{StructuredSig: Dose: DoseRangeModifier}

EDIFACT: Dose Range Modifier (SIG-040-12)

\section{Implementation Guidance - Errata}

ISSUE: An example in the 10.6 implementation guide shows an invalid value, "AND" for this element (12.31.4 Tapered dose, page 367). Corrected in later implementation guides.

RECOMMENDATION: Correct the SCRIPT 10.6 Implementation Guide example or provide the correction in an addendum.

\section{Observation}

The Observation composite has been part of the SCRIPT standard since its early versions, but has not yet been adopted by the industry. However, the content of the segment has been analyzed with respect to correctness / implementability and use of terminology.

Perhaps because it has not been thoroughly assess by the industry, the composite contains issues that would prevent its implementation. The points below identify the key challenges preventing the segment to be used as intended.

\section{Observation: Measurement: Dimension}

EDIFACT: Measurement Dimension, coded (OBS-010-01)

\section{XML Schema Challenge, Implementation Guidance, SCRIPT Enhancement Opportunity, ECL Challenge}

ISSUE: SNOMED and LOINC values allowed by ECL are not allowed by the XML schema.

RECOMMENDATION: Multiple corrections needed in order to create consistency between the 10.6 Implementation Guide, ECL, and XML schema. 


\section{Observation: Measurement: MeasurementDataQualifier}

EDIFACT: Measurement Data Qualifier (OBS-010-06)

\section{XML Schema Challenge, Implementation Guidance, SCRIPT Enhancement Opportunity, ECL Challenge}

ISSUE: (1) Allows specification of terminologies whose values cannot be expressed in the Dimension element (see above).

(2) Further, the element allows an "Other" terminology qualifier, which does not adequately qualify the associated Dimension value the receiving system must interpret.

RECOMMENDATION: (1) Remove XML schema constraints which currently allow only the four X12 DE 738 observation codes.

(2) Remove 4/Other value and replace with specific allowed terminologies, or provide clarification regarding the intended use of the 4/Other qualifier value.

\section{Observation: Measurement: MeasurementSourceCode}

EDIFACT: Source Code List (OBS-010-07)

\section{XML Schema Challenge, Implementation Guidance, ECL Challenge}

ISSUE: (1) The Oct 2010 ECL values don't support the units of measure that would be associated with observations (within the NCI NCPDP subset, the appropriate terminology would be AD, NCI Measurement Unit Code).

(2) The April 2011 ECL appears to mis-document this concept as Measurement Unit Code.

(3) The 10.6 XML schema also holds the erroneous Oct 2010 values. (4) The SCRIPT 10.6 Implementation Guide incorrectly refers to the Units of Presentation terminology in conjunction with this element rather than Measurement Unit Code

RECOMMENDATION: (1) Provide an errata note in October 2010 ECL indicating that the values indicated are incorrect, and that $\mathrm{AD} / \mathrm{NCIt}$ Measurement Unit Code is correct. (2) Correct the current ECL so that Measurement Source Code contains the content currently identified in the ECL as Measurement Unit Code. Provide a cross-reference to the EDIFACT name Source Code List and code 7991. (3) Correct 10.6 XML schema so that the single allowed value is $\mathrm{AD}$.

(4) Correct 10.6 Implementation Guide to replace the reference to Units of Presentation with Measurement Unit Code.

Optional: Include other unit of measure terminologies (SNOMED CT, other) in the ECL and XML schema.

\section{Allergy}

The Allergy segment exists only in the SCRIPT Census message, which is designed for use in longterm and post-acute care settings. The composite is modeled after the allergy concept in the HITSP C32 CCD definition, though small terminology differences have arisen since its introduction-due to subsequent modifications to the C32. 
Below are challenges related to the XML representation of the Allergy segment, including structural and documentation errors. Discussion of the use of standard terminologies in the Allergy segment is discussed further in SCRIPT and Standard Terminologies later in this document.

XML Schema Issues

\section{Allergy: AdverseEvent \\ EDIFACT: Adverse Event Type () \\ Implementation Guidance, ECL Challenge}

ISSUE: XML schema incorrectly defines the AdverseEvent composite as mandatory, which prevents compliance with the business rule "if $\mathrm{Y}$ in NoKnownAllergies, then rest of segment is empty".

RECOMMENDATION: This is an error in the XML schema that NCPDP recognized and corrected in XML 10.11, but not in 10.6. A workaround would be to populate the ItemDescriptionLong filed with a static value like "NONE." The proper handling of this situation should be documented in the 10.6 Implementation Guide or an addendum, to assist implementers.

\section{Allergy: AdverseEvent: CodeListQualifier \\ EDIFACT: Code List Responsibility Agency (ALG-040-03) \\ SCRIPT Enhancement Opportunity}

ISSUE: The current ECL version does not reference this 10.6 concept, as it has been replaced in later NCPDP standards versions with another concept name.

RECOMMENDATION: It would benefit implementers to continue to include all 10.6 concepts in ECL versions during this period in which version 10.6 is being adopted. The current practice of removing references to SCRIPT 10.6 concepts causes implementers time and confusion. See the section elsewhere in this document entitled Handling of concept changes with respect to actively-implemented standards.

\footnotetext{
Allergy: DrugProductCoded: CodeListQualifier

EDIFACT: Code List Responsibility Agency (ALG-050-03)
}

\section{Implementation Guidance, SCRIPT Enhancement Opportunity}

ISSUE: Earlier ECL value lists for this element do not include the specific RxNorm term types; instead has a single "RxNorm" qualifier. The replacement concept, AllergyDrugProductCodedQualifier contains the necessary RxNorm qualifiers but isn't allowed for use with 10.6. 
RECOMMENDATION: (1) It would benefit implementers to enable use of the most recent ECL values for this element.

(2) It is unclear why the typical practice of adjusting ECL value sets over time for existing SCRIPT elements is not followed in the case of this particular element. This may be an instance where a more formal ECL maintenance process for SCRIPT elements would result in greater predictability for implementers.

\section{Allergy: ReactionCoded: CodeListQualifier}

EDIFACT: Code List Responsibility Agency (ALG-060-03)

\section{SCRIPT Enhancement Opportunity}

ISSUE: The current ECL version does not reference this 10.6 concept, as it has been replaced in later NCPDP standards versions with another concept name.

RECOMMENDATION: It would benefit implementers to continue to include all 10.6 concepts in ECL versions during this period in which version 10.6 is being adopted. The current practice of removing references to SCRIPT 10.6 concepts causes implementers time and confusion. See the section elsewhere in this document entitled Handling of concept changes with respect to actively-implemented standards.

\section{Schema documentation issues}

ISSUE: The XML schema annotations for the following elements is incomplete-- referencing "X" as the related EDIFACT element, rather than actual EDIFACT element IDs

\section{Allergy: AdverseEvent: ItemDescriptionLong} EDIFACT: Item Description Long (ALG-040-01)

Allergy: AdverseEvent: ItemNumber EDIFACT: Item Number (ALG-040-02)

\section{Allergy: DrugProductCoded: ItemDescriptionLong}

EDIFACT: Item Description Long (ALG-050-01)

\section{Allergy: DrugProductCoded: ItemNumber}

EDIFACT: Item Number (ALG-050-02)

\section{Allergy: ReactionCoded: ItemDescriptionLong \\ EDIFACT: Item Description Long (ALG-060-01)}

Allergy: ReactionCoded: ItemNumber

EDIFACT: Item Number (ALG-060-02)

\section{Allergy: SeverityCoded: ItemDescriptionLong EDIFACT: Item Description Long (ALG-070-01)}

\section{Allergy: SeverityCoded: ItemNumber}

EDIFACT: Item Number (ALG-070-02) 
RECOMMENDATION: Correct the annotations in the 10.6 XML schema, to assist implementers

\section{Diagnosis}

The Diagnosis segment exists only in the SCRIPT Census message, which is designed for use in long-term and post-acute care settings. The composite is modeled after the problem concept in the HITSP C32 CCD definition, though small terminology differences have arisen since its introduction —due to subsequent modifications to the C32.

Below are challenges related to the XML representation of the Diagnosis segment, including structural and documentation errors. Discussion of the use of standard terminologies in the segment is discussed further in SCRIPT and Standard Terminologies later in this document.

\section{XML Schema Issues}

\section{DiagnosisGeneral: ProblemType: CodeListQualifier}

EDIFACT: Code List Responsibility Agency (DIA-030-03)

\section{SCRIPT Enhancement Opportunity}

ISSUE: The current ECL version does not reference this 10.6 concept, as it has been replaced in later NCPDP standards versions with another concept name.

RECOMMENDATION: It would benefit implementers to continue to include all 10.6 concepts in ECL versions during this period in which version 10.6 is being adopted. The current practice of removing references to SCRIPT 10.6 concepts causes implementers time and confusion. See the section elsewhere in this document entitled Handling of concept changes with respect to actively-implemented standards.

\section{DiagnosisGeneral: ProblemNameCoded}

EDIFACT: ProblemNameCoded (DIA-040)

\section{XML Schema Challenge}

ISSUE: An error exists in the 10.6 XML schema related to this composite: The schema should allow up to two occurrences of ProblemNameCoded (per the 10.6 Implementation Guide), but only allows one.

RECOMMENDATION: Correct the 10.6 schema to allow up to two occurrences of ProblemNameCoded.

\section{Schema documentation issues}

ISSUE: The XML schema annotations for the following elements is incomplete-- referencing "X" as the related EDIFACT element, rather than actual EDIFACT element IDs

DiagnosisGeneral: ProblemType: ItemDescriptionLong EDIFACT: Item Description Long (DIA-030-01) 


\section{DiagnosisGeneral: ProblemType: ItemNumber}

EDIFACT: Item Number (DIA-030-02)

\section{DiagnosisGeneral: ProblemNameCoded: ItemDescriptionLong \\ EDIFACT: Item Description Long (DIA-040-01)}

\section{DiagnosisGeneral: ProblemNameCoded: ItemNumber}

EDIFACT: Item Number (DIA-040-02)

RECOMMENDATION: Correct the annotations in the 10.6 XML schema, to assist implementers

\section{Challenges impacting SCRIPT elements in multiple segments}

Below is further discussion of challenges common to elements in multiple segments of the SCRIPT 10.6 standard, all of which are identified briefly in the impacted composite-specific sections above.

\section{Address Line 2 representation}

AddressLine2 and PlaceLocationQualifier address elements appear in multiple SCRIPT elements. Below is a description of challenges associated with the mapping of the concepts to the XML format.

\section{Address: AddressLine2}

EDIFACT: Place / Location (PVD-080-06)

Address: PlaceLocationQualifier

EDIFACT: Place / Location Qualifier (PVD-080-05)

\section{Implementation Guidance, XML Schema Challenge}

ISSUE: The XML documentation is not clear regarding how these EDIFACT elements map to the AddressLine2 XML concept. The EDIFACT version of SCRIPT 10.6 doesn't contain a dedicated Address Line 2 element; instead, it has a trading partner-defined "Place/Location" with an associated "Place/Location Qualifier" element whose values are also trading partnerdefined. These are imperfectly reflected in the XML format as AddressLine2. The XML also contains a PlaceLocation Qualifier element which apparently serves no purpose.

RECOMMENDATION: Provide mapping information to the SCRIPT 10.6 Implementation Guide and/or XML schema clarifying the relationship between these XML concepts and their EDIFACT counterparts. Eliminate the PlaceLocationQualifier element in the XML Schema.

\section{XML element cardinality issues}

\section{Identification}

EDIFACT: Reference Number (elements in multiple segments)

\section{Implementation Guidance, XML Schema Challenge}

ISSUE: In the 10.6 Implementation Guide, the number of occurrences of several identifier elements is constrained (prescriber, supervisor, pharmacy and facility Identification limited to three occurrences, patient Identification to two), but the XML format allows unlimited occurrences. 
RECOMMENDATION: Resolve the inconsistency in the number of allowed Identification instances and provide implementation guidance by updating the XML schema and annotations and/or providing a correction to the 10.6 Implementation Guide.

\section{ECL Identification concept mixes identifier types}

\section{Identification}

EDIFACT: Reference Number (elements in multiple segments)

\section{XML Schema Challenge, Implementation Guidance, SCRIPT Enhancement Opportunity}

ISSUE: This ECL concept mixes identifier types for pharmacies, providers, facilities or patients. Only a subset of these are appropriate for each element, and the remainder are inappropriate.

RECOMMENDATION: In the ECL, in cases where not all values for a concept are applicable in all composite / element instances where it appears, provide a separate set of code values for each instance containing only the applicable values. Update the XML schema accordingly. (See the section elsewhere in this document entitled Consolidation of terms and values from dissimilar standards for additional background)

\section{Lacking state qualifiers for certain identifiers}

\section{Identification}

EDIFACT: Reference Number (qualified for State License Number and DEA Number)

\section{SCRIPT Enhancement Opportunity}

ISSUE: The State License Number and DEA Number elements do not include associated state qualifiers. This may present an issue when the prescriber or pharmacy is licensed in more than one state or a prescriber is registered with the DEA in more than one state.

RECOMMENDATION: Consider adding state qualifiers for state license number and DEA number elements, to clarify the issuing state.

No differentiation between Individual and Organizational NPI and DEA

\section{Identification}

EDIFACT: Reference Number (PVD-020-01 (value), PVD-020-02 (qualifier))

\section{XML Schema Challenge, Implementation Guidance, SCRIPT Enhancement Opportunity}

ISSUE: The concept does not enable differentiation between individual and institutional NPIs and DEA Numbers. While the type of identifier can typically be inferred from the identifier's location (e.g., in the prescriber segment versus the pharmacy), exceptions exist-such as a resident physician using their hospital's DEA number, or a prescriber with a single-person practice identified with their organizational NPI. In addition, DEA suffixes are not explicitly 
supported, such as those assigned to practitioners that prescribe controlled substances under the authority of their institution. Today, DEA suffixes are placed after the DEA number in the same element, and proper interpretation of the suffix depends on participants following a formatting convention to separate the suffix from the DEA number.

RECOMMENDATION: Consider adding NPI and DEA Number types that specify whether the IDs are individual or organizational (e.g., individual NPI, organizational DEA Number). Add explicit support for DEA suffix.

\section{Other SCRIPT document errata}

This section identifies other guidance in the SCRIPT 10.6 Implementation Guide and related documents that is unclear or contains errors that could cause challenges for implementers relying on the information.

\section{Implementation of ePrescribing Standards}

(201009.Read.me.eprescribing.pdf)

Location: Page 3, top. Section: NCPDP SCRIPT Standard Implementation Guide Version 10.6

Text: "Data Dictionary (for field definitions and formats) - 10/2005"

ISSUE: "10/2005" should instead be "10/2008", to match the table that follows, indicating that the correct data dictionary version for SCRIPT 10.6 is the October 2008 version.

Text: "External Code List (for field values) - most current"

ISSUE (1): The most current version of the External Code List no longer contains certain concepts that have been replaced with new concepts in more recent SCRIPT versions, including:

7943 - Administration Timing Code Qualifier - SIG Segment

7919 -Body Metric Qualifier - SIG Segment

7923 - Calculated Dose Unit of Measure Code Qualifier - SIG Segment

7893 - Change of Prescription Status Flag

$681 \varnothing$ - Clinical Information Qualifier

Others

It would be preferable for implementers to be able to use a single ECL version when implementing SCRIPT 10.6, rather than needing to reference older ECL versions for certain elements that are no longer present in more recent ECL versions.

ISSUE (2): The recommendation to use the most recent ECL version is unique to this document. Elsewhere, it is stated that use of the October 2008 ECL up to the most recent is allowed, but no recommendation is made. It would be beneficial to implementers for NCPDP to give clear and consistent guidance regarding the ECL version to be used, and further to integrate the preferred version into the SCRIPT 10.6 XML schema. See XML Schema and ECL Version elsewhere in this document.

\section{External Code List (ECL)}

(external_code_list_201104.pdf)

Location: Page 269, top. Section: V. APPENDIX V-CODE SET QUALIFIER VALUES

Text: "Value 2 =FMT Federal Medication Therapy"

ISSUE: "Therapy" should instead be "Terminology" 
(C) 1st American Systems and Services LLC Page 35 www.1asas.com 


\section{SCRIPT and Standard Terminologies}

The SCRIPT standard incorporates external terminologies via its External Code List (ECL) (see Management of "External Code Lists" elsewhere in this document), for use in identifying...

- medications (RxNorm, NDC)

- substances (UNII)

- drug classes (NDF-RT)

- a drug's pharmaceutical characteristics such as dosage form (NCI FDA and SNOMED CT)

- other clinical concepts related to administration directions (SNOMED CT and FMT terminologies)

- allergies (SNOMED CT in conjunction with medication, substance and drug class terminologies)

- diagnoses (SNOMED CT, ICD-9, ICD10).

In certain cases, NCPDP has sought consistency of terminology use with other health information exchange standards such as the HITSP C32 CCD, in other cases consistency was previously achieved but later lost due to changes by other standards, and in other cases SCRIPT's terminology use is unique to itself. Another project deliverable, Standards Compatibility in Medication Reconciliation, assesses SCRIPT's terminology use versus that of the C32 CCD and ASTM CCR in detail. Below are summarized points from that analysis that focus on...

- challenges for implementers created by SCRIPT's terminology use

- opportunities to improve SCRIPT support for terminologies in terms of consistency with other standards and ease of implementation.

\section{Current terminology in SCRIPT, challenges and recommendations}

Below is a summary of current medication and clinical terminology used in SCRIPT 10.6, noting consistency with the C32 CCD and CCR, and identifying challenges and recommendations for SCRIPT.

\begin{tabular}{|c|c|c|c|}
\hline \multicolumn{2}{|r|}{ SCRIPT Terminology } & $\begin{array}{c}\text { Compatibility } \\
\text { with C32 CCD } \\
\text { and CCR }\end{array}$ & Challenges and Recommendations \\
\hline \multicolumn{4}{|c|}{$\begin{array}{l}\text { Drug Product and Prescribed / } \\
\text { Dispensed Qty }\end{array}$} \\
\hline $\begin{array}{l}\text { Medication } \\
\text { Product }\end{array}$ & $\begin{array}{l}\text { NewRx: RxNorm and } \\
\text { RxNorm sources (per MU } \\
\text { restrictions) } \\
\text { MedHistory, FillStatus: } \\
\text { RxNorm and others } \\
\text { including proprietary drug } \\
\text { databases }\end{array}$ & $\begin{array}{l}\text { Where } \\
\text { Meaningful Use } \\
\text { rules apply, } \\
\text { SCRIPT, CCD } \\
\text { and CCR all use } \\
\text { RxNorm. } \\
\text { Support for } \\
\text { RxNorm is in } \\
\text { place across }\end{array}$ & $\begin{array}{l}\text { ISSUE: A gap in RxNorm support exists in the Allergy } \\
\text { drug co-agent element (Allergy: DrugProductCoded: } \\
\text { CodeListQualifier). Unlike in other SCRIPT elements } \\
\text { supporting RxNorm, the individual RxNorm qualifiers } \\
\text { (SBD, SCD, BPK, GPK) are not allowed, but instead a } \\
\text { single "RxNorm" qualifier. The impact of this omission is } \\
\text { small, as it doesn't prevent implementers from using } \\
\text { these RxNorm concepts- since the more specific } \\
\text { qualifiers aren't needed to uniquely convey these } \\
\text { concepts. }\end{array}$ \\
\hline
\end{tabular}




\begin{tabular}{|c|c|c|c|}
\hline Concept & SCRIPT Terminology & $\begin{array}{c}\text { Compatibility } \\
\text { with C32 CCD } \\
\text { and CCR }\end{array}$ & Challenges and Recommendations \\
\hline & & SCRIPT. & $\begin{array}{l}\text { RECOMMENDATION: Add the separate SBD, SCD, } \\
\text { BPK, GPK qualifiers to the ECL for this element. }\end{array}$ \\
\hline $\begin{array}{l}\text { Commercial } \\
\text { Product, Brand } \\
\text { Name }\end{array}$ & $\begin{array}{l}\text { NDC11 of generic or brand } \\
\text { product, as prescribed } \\
\text { (NewRx, FillStatus) or } \\
\text { dispensed (MedHistory, } \\
\text { FillStatus) }\end{array}$ & $\begin{array}{l}\text { SCRIPT, CCD } \\
\text { and CCR all use } \\
\text { NDCs to identify } \\
\text { commercial } \\
\text { packaged } \\
\text { products }\end{array}$ & No challenges or recommendations. \\
\hline Dosage Form & $\begin{array}{l}\text { NCI NCPDP StrengthForm } \\
\text { (NCI subset code C89508). } \\
\text { Subset of NCI FDA } \\
\text { Pharmaceutical Dosage } \\
\text { Form: C42636. } \\
\text { Corresponds to the SPL } \\
\text { Pharmaceutical Dosage } \\
\text { Form (NCI subset } \\
\text { C54456), with some } \\
\text { omissions }\end{array}$ & $\begin{array}{l}\text { CCD, Med } \\
\text { History and CCR: } \\
\text { When present, } \\
\text { terminology is } \\
\text { compatible }\end{array}$ & $\begin{array}{l}\text { ISSUE: Both the CCD and SCRIPT standards use } \\
\text { National Cancer Institute code sets to represent dosage } \\
\text { forms, though with some differences. The C32 CCD } \\
\text { limits values to the NCI pharmaceutical dosage form } \\
\text { terminology (C42636), whereas NCI provides a subset of } \\
\text { those terms for use in SCRIPT. However, NCPDP allows } \\
\text { implementers to use additional NCI values not contained } \\
\text { in the subset. } \\
\text { RECOMMENDATION: Take steps to further align } \\
\text { and/or reconcile the particular set of NCI-FDA values } \\
\text { available for SCRIPT with those specified in C32 CCD. }\end{array}$ \\
\hline $\begin{array}{l}\text { Strength Unit of } \\
\text { Measure }\end{array}$ & $\begin{array}{l}\text { NCI NCPDP Strength Unit } \\
\text { of Measure (NCI subset } \\
\text { code 89509). Corresponds } \\
\text { to the SPL Potency } \\
\text { Terminology (NCI subset } \\
\text { C54458) but lacking some } \\
\text { SPL codes and containing } \\
\text { codes not in SPL }\end{array}$ & $\begin{array}{l}\text { Not directly } \\
\text { comparable } \\
\text { between } \mathrm{CCD} \text {, } \\
\mathrm{CCR} \text {, and Med } \\
\text { History. Optional } \\
\text { in all, with } \\
\text { different coding }\end{array}$ & $\begin{array}{l}\text { ISSUE: The NCI subset managed for NCPDP is } \\
\text { essentially the same as the Structured Product Language } \\
\text { (SPL) Potency Code set, but with minor differences. } \\
\text { These differences may cause challenges in processes } \\
\text { where SCRIPT information is consolidated with data } \\
\text { conforming to SPL. } \\
\text { RECOMMENDATION: Consider aligning and/or } \\
\text { reconciling the NCI/SCRIPT Strength Unit of Measure } \\
\text { with the SPL Potency Terminology, to aid those } \\
\text { integrating the two standards in a workflow. }\end{array}$ \\
\hline Medication type & $n / a$ & $\begin{array}{l}\text { Only supported } \\
\text { by the CCD }\end{array}$ & $\begin{array}{l}\text { No challenges or recommendations. Medication Type } \\
\text { (Over-the-counter versus prescription) can be reliably } \\
\text { determined based on the drug identifier in combination } \\
\text { with other drug data sources }\end{array}$ \\
\hline
\end{tabular}




\begin{tabular}{|c|c|c|c|}
\hline Concept & SCRIPT Terminology & $\begin{array}{l}\text { Compatibility } \\
\text { with C32 CCD } \\
\text { and CCR } \\
\end{array}$ & Challenges and Recommendations \\
\hline $\begin{array}{l}\text { Ordered Quantity } \\
\text { Unit of Measure }\end{array}$ & $\begin{array}{l}\text { NCI NCPDP Quantity Unit } \\
\text { of Measure (NCI subset } \\
\text { code 89510). Corresponds } \\
\text { primarily to the SPL Unit } \\
\text { of Presentation (NCI } \\
\text { C87300) but lacks some of } \\
\text { those values. Also includes } \\
\text { terms in SPL Potency } \\
\text { (subset C54458) and Unit } \\
\text { Of Measure (subset } \\
\text { C92951) terminologies. }\end{array}$ & $\begin{array}{l}\text { C32 CCD and } \\
\text { NCPDP Med } \\
\text { History / CCR use } \\
\text { different NCI } \\
\text { FDA } \\
\text { terminologies. }\end{array}$ & $\begin{array}{l}\text { ISSUE: The Medication History (and CCR by reference) } \\
\text { use a subset of the NCI Unit of Presentation terminology } \\
\text { (C87300) whereas the C } 32 \text { CCD uses the NCI } \\
\text { Pharmaceutical Dosage Form terminology (C42636). } \\
\text { (For dose units of administration, the situation is } \\
\text { reversed, with the C32 CCD using units of presentation } \\
\text { and Medication History / CCR using pharmaceutical } \\
\text { dosage form.) } \\
\text { RECOMMENDATION: Work with owners of the C32 to } \\
\text { align and/or reconcile the NCI/SCRIPT Unit of } \\
\text { Presentation terminology with the NCI Pharmaceutical } \\
\text { Dosage Form terminology used in the C32 CCD, to aid } \\
\text { those integrating the two standards in a workflow. }\end{array}$ \\
\hline Medication Status & $n / a$ & $\begin{array}{l}\text { Not supported by } \\
\text { the Medication } \\
\text { History message }\end{array}$ & $\begin{array}{l}\text { No challenges or recommendations. Medication History } \\
\text { data sources are not in a position to know whether a } \\
\text { medication is being actively taken by the patient. }\end{array}$ \\
\hline $\begin{array}{l}\text { Interactions } \\
\text { considered }\end{array}$ & $\begin{array}{l}\text { CoAgent: RxNorm } \\
\text { Other: Proprietary NCPDP } \\
\text { code values }\end{array}$ & $\begin{array}{l}\text { Only in the } \\
\text { SCRIPT New } \\
\text { Prescription }\end{array}$ & No challenges or recommendations. \\
\hline \multicolumn{4}{|c|}{ Medication Administration } \\
\hline $\begin{array}{l}\text { Free Text } \\
\text { Directions }\end{array}$ & $\mathrm{n} / \mathrm{a}$ & $\begin{array}{l}\text { Free text } \\
\text { directions ("sig") } \\
\text { not mandatory in } \\
\text { the CCD or CCR }\end{array}$ & No challenges or recommendations. \\
\hline Delivery Method & $\begin{array}{l}\text { Recommended: SNOMED } \\
\text { CT. No constraints } \\
\text { specified. } \\
\text { Allowed: FMT (particular } \\
\text { terminology not specified. } \\
\text { Presume NCI) }\end{array}$ & $\begin{array}{l}\text { Optional in all } \\
\text { reviewed } \\
\text { standards. } \\
\text { Consistent } \\
\text { terminology. }\end{array}$ & $\begin{array}{l}\text { ISSUE: SCRIPT } 10.6 \text { and Structured Sig } 1.1 \\
\text { Implementation Guides conflict: } 10.6 \text { allows FMT, but } \\
\text { Structured Sig recommends only SNOMED CT be used. } \\
\text { RECOMMENDATION: Make SCRIPT } 10.6 \text { and } \\
\text { Structured Sig } 1.1 \text { guidance consistent, to assist } \\
\text { implementers. }\end{array}$ \\
\hline
\end{tabular}




\begin{tabular}{|c|c|c|c|}
\hline Concept & SCRIPT Terminology & $\begin{array}{c}\text { Compatibility } \\
\text { with C32 CCD } \\
\text { and CCR }\end{array}$ & Challenges and Recommendations \\
\hline $\begin{array}{l}\text { Delivery Method } \\
\text { Modifier }\end{array}$ & $\begin{array}{l}\text { Recommended: SNOMED } \\
\text { CT. No constraints } \\
\text { specified.Allowed: FMT } \\
\text { (particular terminology not } \\
\text { specified. Presume NCI) }\end{array}$ & $\begin{array}{l}\text { Only supported in } \\
\text { the SCRIPT } \\
\text { standard. }\end{array}$ & $\begin{array}{l}\text { ISSUE: SCRIPT } 10.6 \text { and Structured Sig } 1.1 \\
\text { Implementation Guides conflict: } 10.6 \text { allows FMT, but } \\
\text { Structured Sig recommends only SNOMED CT be used. } \\
\text { RECOMMENDATION: Make SCRIPT } 10.6 \text { and } \\
\text { Structured Sig } 1.1 \text { guidance consistent, to assist } \\
\text { implementers. }\end{array}$ \\
\hline $\begin{array}{l}\text { Dose Unit of } \\
\text { Administration }\end{array}$ & $\begin{array}{l}\text { Recommended: SNOMED } \\
\text { CT. No constraints } \\
\text { specified. } \\
\text { Allowed: FMT (particular } \\
\text { terminology not specified. } \\
\text { Presume NCI NCPDP } \\
\text { StrengthForm, as specified } \\
\text { for the FormCode element, } \\
\text { above }\end{array}$ & $\begin{array}{l}\text { C32 CCD and } \\
\text { NCPDP Med } \\
\text { History / CCR use } \\
\text { different NCI } \\
\text { FDA } \\
\text { terminologies. } \\
\text { CCD includes the } \\
\text { Unit of } \\
\text { Presentation name } \\
\text { only (rather than } \\
\text { the code value) }\end{array}$ & $\begin{array}{l}\text { ISSUE: (1) The Medication History (and CCR by } \\
\text { reference) use a subset of the NCI Pharmaceutical } \\
\text { Dosage Form terminology (C42636), whereas the C32 } \\
\text { CCD uses the NCI Unit of Presentation terminology } \\
\text { (C87300). (2) SCRIPT } 10.6 \text { and Structured Sig v1.1 IGs } \\
\text { conflict regarding FMT being allowed for this element. } \\
\text { RECOMMENDATION: (1) (2) Work with owners of the } \\
\text { C32 to align and/or reconcile the NCI/SCRIPT Strength } \\
\text { Form terminology with the NCI Unit of Presentation } \\
\text { terminology used in the C32 CCD, and consider } \\
\text { recommending the NCI FDA codes in Structured Sig to } \\
\text { aid those integrating the two standards in a workflow. }\end{array}$ \\
\hline $\begin{array}{l}\text { Maximum Dose } \\
\text { Unit of } \\
\text { Administration }\end{array}$ & $\begin{array}{l}\text { Recommended: SNOMED } \\
\text { CT. No constraints } \\
\text { specified. } \\
\text { Allowed: FMT (particular } \\
\text { terminology not specified. } \\
\text { Presume NCI NCPDP } \\
\text { StrengthForm, as specified } \\
\text { for the FormCode element, } \\
\text { above }\end{array}$ & $\begin{array}{l}\text { C32 CCD and } \\
\text { NCPDP Med } \\
\text { History / CCR use } \\
\text { different NCI } \\
\text { FDA } \\
\text { terminologies. } \\
\text { CCD includes the } \\
\text { Unit of } \\
\text { Presentation name } \\
\text { only }\end{array}$ & See Dose Unit of Administration comment, above. \\
\hline $\begin{array}{l}\text { Route of } \\
\text { Administration }\end{array}$ & $\begin{array}{l}\text { Recommended: SNOMED } \\
\text { CT. No constraints } \\
\text { specified. } \\
\text { Allowed: FMT (particular } \\
\text { terminology not specified. } \\
\text { Presume NCI FDA } \\
\text { RouteOfAdministration } \\
\text { terminology) }\end{array}$ & $\begin{array}{l}\text { Different } \\
\text { terminologies } \\
\text { used }\end{array}$ & $\begin{array}{l}\text { ISSUE: (1) The NCPDP Medication History (and the } \\
\text { CCR, which refers to NCPDP Structured Sig) use } \\
\text { SNOMED CT, and the C32 CCD uses NCI FDA. } \\
\text { (2) SCRIPT } 10.6 \text { and Structured Sig v1.1 IGs conflict } \\
\text { regarding FMT being allowed for this element. } \\
\text { RECOMMENDATION: (1) (2) Consider recommending } \\
\text { use of NCI FDA Route of Administration in SCRIPT as is } \\
\text { used in the C32 CCD, to aid those integrating the } \\
\text { standards in a workflow. }\end{array}$ \\
\hline $\begin{array}{l}\text { Site of } \\
\text { Administration }\end{array}$ & $\begin{array}{l}\text { Recommended: SNOMED } \\
\text { CT. No constraints } \\
\text { specified.Allowed: FMT } \\
\text { (particular terminology not } \\
\text { specified. Presume NCI) }\end{array}$ & $\begin{array}{l}\text { Optional in all } \\
\text { reviewed } \\
\text { standards. } \\
\text { Roughly } \\
\text { consistent } \\
\text { terminology. }\end{array}$ & $\begin{array}{l}\text { ISSUE: SCRIPT } 10.6 \text { and Structured Sig } 1.1 \\
\text { Implementation Guides conflict: } 10.6 \text { allows FMT, but } \\
\text { Structured Sig recommends only SNOMED CT be used. } \\
\text { RECOMMENDATION: Make SCRIPT } 10.6 \text { and } \\
\text { Structured Sig } 1.1 \text { guidance consistent, to assist } \\
\text { implementers. }\end{array}$ \\
\hline
\end{tabular}




\begin{tabular}{|c|c|c|c|}
\hline Concept & SCRIPT Terminology & $\begin{array}{c}\text { Compatibility } \\
\text { with C32 CCD } \\
\text { and CCR }\end{array}$ & Challenges and Recommendations \\
\hline $\begin{array}{l}\text { Administration } \\
\text { Timing } \\
\text { (descriptive or } \\
\text { based on activities } \\
\text { of daily living) }\end{array}$ & $\begin{array}{l}\text { Recommended: SNOMED } \\
\text { CT. No constraints } \\
\text { specified. } \\
\text { Allowed: FMT (particular } \\
\text { terminology not specified. } \\
\text { Presume NCI) }\end{array}$ & $\begin{array}{l}\text { Different } \\
\text { terminologies } \\
\text { used - CCD uses } \\
\text { proprietary HL7 } \\
\text { terms }\end{array}$ & $\begin{array}{l}\text { ISSUE: SCRIPT } 10.6 \text { and Structured Sig } 1.1 \\
\text { Implementation Guides conflict: } 10.6 \text { allows FMT, but } \\
\text { Structured Sig recommends only SNOMED CT be used. } \\
\text { RECOMMENDATION: Make SCRIPT } 10.6 \text { and } \\
\text { Structured Sig } 1.1 \text { guidance consistent, to assist } \\
\text { implementers. }\end{array}$ \\
\hline $\begin{array}{l}\text { Frequency Time } \\
\text { Period }\end{array}$ & $\begin{array}{l}\text { Recommended: SNOMED } \\
\text { CT. No constraints } \\
\text { specified. } \\
\text { Allowed: FMT (particular } \\
\text { terminology not specified. } \\
\text { Presume NCI) }\end{array}$ & $\begin{array}{l}\text { Different } \\
\text { terminologies } \\
\text { used - CCD uses } \\
\text { proprietary HL7 } \\
\text { terms }\end{array}$ & $\begin{array}{l}\text { ISSUE: SCRIPT } 10.6 \text { and Structured Sig } 1.1 \\
\text { Implementation Guides conflict: } 10.6 \text { allows FMT, but } \\
\text { Structured Sig recommends only SNOMED CT be used. } \\
\text { RECOMMENDATION: Make SCRIPT } 10.6 \text { and } \\
\text { Structured Sig } 1.1 \text { guidance consistent, to assist } \\
\text { implementers. }\end{array}$ \\
\hline $\begin{array}{l}\text { Interval Time } \\
\text { Period }\end{array}$ & $\begin{array}{l}\text { Recommended: SNOMED } \\
\text { CT. No constraints } \\
\text { specified.Allowed: FMT } \\
\text { (particular terminology not } \\
\text { specified. Presume NCI) }\end{array}$ & $\begin{array}{l}\text { Different } \\
\text { terminologies } \\
\text { used - CCD uses } \\
\text { proprietary HL7 } \\
\text { terms }\end{array}$ & $\begin{array}{l}\text { ISSUE: SCRIPT } 10.6 \text { and Structured Sig } 1.1 \\
\text { Implementation Guides conflict: } 10.6 \text { allows FMT, but } \\
\text { Structured Sig recommends only SNOMED CT be used. } \\
\text { RECOMMENDATION: Make SCRIPT } 10.6 \text { and } \\
\text { Structured Sig } 1.1 \text { guidance consistent, to assist } \\
\text { implementers. }\end{array}$ \\
\hline Duration Period & $\begin{array}{l}\text { Recommended: SNOMED } \\
\text { CT. No constraints } \\
\text { specified. } \\
\text { Allowed: FMT (particular } \\
\text { terminology not specified. } \\
\text { Presume NCI) }\end{array}$ & $\begin{array}{l}\text { Different } \\
\text { terminologies } \\
\text { used - CCD uses } \\
\text { proprietary HL7 } \\
\text { terms }\end{array}$ & $\begin{array}{l}\text { ISSUE: SCRIPT } 10.6 \text { and Structured Sig } 1.1 \\
\text { Implementation Guides conflict: } 10.6 \text { allows FMT, but } \\
\text { Structured Sig recommends only SNOMED CT be used. } \\
\text { RECOMMENDATION: Make SCRIPT } 10.6 \text { and } \\
\text { Structured Sig } 1.1 \text { guidance consistent, to assist } \\
\text { implementers. }\end{array}$ \\
\hline $\begin{array}{l}\text { Rate of } \\
\text { Administration }\end{array}$ & $\begin{array}{l}\text { Recommended: SNOMED } \\
\text { CT. No constraints } \\
\text { specified. } \\
\text { Allowed: FMT (particular } \\
\text { terminology not specified. } \\
\text { Presume NCI) }\end{array}$ & $\begin{array}{l}\text { Different } \\
\text { terminologies } \\
\text { used - CCD uses } \\
\text { proprietary HL7 } \\
\text { terms }\end{array}$ & $\begin{array}{l}\text { ISSUE: SCRIPT } 10.6 \text { and Structured Sig } 1.1 \\
\text { Implementation Guides conflict: } 10.6 \text { allows FMT, but } \\
\text { Structured Sig recommends only SNOMED CT be used. } \\
\text { RECOMMENDATION: Make SCRIPT } 10.6 \text { and } \\
\text { Structured Sig } 1.1 \text { guidance consistent, to assist } \\
\text { implementers. }\end{array}$ \\
\hline $\begin{array}{l}\text { Calculated Dose } \\
\text { Time Period }\end{array}$ & $\begin{array}{l}\text { Recommended: SNOMED } \\
\text { CT. } \\
\text { Allowed: FMT (particular } \\
\text { terminology not specified. } \\
\text { Presume NCI) }\end{array}$ & $\begin{array}{l}\text { Different } \\
\text { terminologies } \\
\text { used - CCD uses } \\
\text { proprietary HL7 } \\
\text { terms }\end{array}$ & $\begin{array}{l}\text { ISSUE: SCRIPT } 10.6 \text { and Structured Sig } 1.1 \\
\text { Implementation Guides conflict: } 10.6 \text { allows FMT, but } \\
\text { Structured Sig recommends only SNOMED CT be used. } \\
\text { RECOMMENDATION: Make SCRIPT } 10.6 \text { and } \\
\text { Structured Sig } 1.1 \text { guidance consistent, to assist } \\
\text { implementers. }\end{array}$ \\
\hline $\begin{array}{l}\text { Maximum Dose } \\
\text { Time Period }\end{array}$ & $\begin{array}{l}\text { Recommended: SNOMED } \\
\text { CT. No constraints } \\
\text { specified. } \\
\text { Allowed: FMT (particular } \\
\text { terminology not specified. } \\
\text { Presume NCI) }\end{array}$ & $\begin{array}{l}\text { Different } \\
\text { terminologies } \\
\text { used - CCD uses } \\
\text { proprietary HL7 } \\
\text { terms }\end{array}$ & $\begin{array}{l}\text { ISSUE: SCRIPT } 10.6 \text { and Structured Sig } 1.1 \\
\text { Implementation Guides conflict: } 10.6 \text { allows FMT, but } \\
\text { Structured Sig recommends only SNOMED CT be used. } \\
\text { RECOMMENDATION: Make SCRIPT } 10.6 \text { and } \\
\text { Structured Sig } 1.1 \text { guidance consistent, to assist } \\
\text { implementers. }\end{array}$ \\
\hline
\end{tabular}

(C) 1st American Systems and Services LLC Page 40 


\begin{tabular}{|c|c|c|c|}
\hline \multicolumn{2}{|r|}{ SCRIPT Terminology } & $\begin{array}{c}\text { Compatibility } \\
\text { with C32 CCD } \\
\text { and CCR } \\
\end{array}$ & Challenges and Recommendations \\
\hline \multicolumn{4}{|c|}{ Indication for medication use } \\
\hline $\begin{array}{l}\text { Indication } \\
\text { Precursor Text }\end{array}$ & $\begin{array}{l}\text { Recommended: SNOMED } \\
\text { CT. No constraints } \\
\text { specified. } \\
\text { Allowed: FMT (particular } \\
\text { terminology not specified. } \\
\text { Presume NCI) }\end{array}$ & $\begin{array}{l}\text { Only supported in } \\
\text { the SCRIPT } \\
\text { standard. }\end{array}$ & $\begin{array}{l}\text { ISSUE: SCRIPT } 10.6 \text { and Structured Sig } 1.1 \\
\text { Implementation Guides conflict: } 10.6 \text { allows FMT, but } \\
\text { Structured Sig recommends only SNOMED CT be used. } \\
\text { RECOMMENDATION: Make SCRIPT } 10.6 \text { and } \\
\text { Structured Sig } 1.1 \text { guidance consistent, to assist } \\
\text { implementers. }\end{array}$ \\
\hline $\begin{array}{l}\text { Indication for } \\
\text { medication } \\
\text { administration } \\
\text { (optionally in } \\
\text { conjunction with } \\
\text { an observation) }\end{array}$ & $\begin{array}{l}\text { Recommended: SNOMED } \\
\text { CT. No constraints } \\
\text { specified. } \\
\text { Allowed: FMT (particular } \\
\text { terminology not specified. } \\
\text { Presume NCI) }\end{array}$ & $\begin{array}{l}\text { Both CCD and } \\
\text { SCRIPT once } \\
\text { conformed to the } \\
\text { VA/KP SNOMED } \\
\text { problem list } \\
\text { subset, but } \\
\text { SCRIPT ECL } \\
\text { does not reflect a } \\
\text { subsequent } \\
\text { change to that } \\
\text { subset }\end{array}$ & $\begin{array}{l}\text { ISSUE: (1) The allowed set of SNOMED CT codes is } \\
\text { restricted further in the C32 CCD than in the NCPDP or } \\
\text { CCR standards. (2) SCRIPT } 10.6 \text { and Structured Sig } 1.1 \\
\text { Implementation Guides conflict: } 10.6 \text { allows FMT, but } \\
\text { Structured Sig recommends only SNOMED CT be used. } \\
\text { RECOMMENDATION: (1) Bring SCRIPT ECL into } \\
\text { consistency with HITSP C32 CCD by conforming to the } \\
\text { VA/KP SNOMED problem list subset. (2) Make SCRIPT } \\
10.6 \text { and Structured Sig } 1.1 \text { guidance consistent, to assist } \\
\text { implementers. }\end{array}$ \\
\hline $\begin{array}{l}\text { Indication value } \\
\text { unit of measure }\end{array}$ & $\begin{array}{l}\text { Recommended: SNOMED } \\
\text { CT. No constraints } \\
\text { specified. } \\
\text { Allowed: FMT } \\
\text { **Note: inconsistent with } \\
\text { SCRIPT element, } \\
\text { Observation } \\
\text { MeasurementUnitCode, } \\
\text { which only allows FMT / } \\
\text { NCI MeasurementUnit } \\
\text { terms }\end{array}$ & $\begin{array}{l}\text { Optional in all } \\
\text { reviewed } \\
\text { standards. Non- } \\
\text { specific guidance } \\
\text { in all. Internal } \\
\text { SCRIPT } \\
\text { inconsistency. }\end{array}$ & $\begin{array}{l}\text { ISSUE: (1) This concept is coded differently within } \\
\text { SCRIPT (between the Observation segment and } \\
\text { Structured Sig). (2) SCRIPT } 10.6 \text { and Structured Sig } 1.1 \\
\text { Implementation Guides conflict: } 10.6 \text { allows FMT, but } \\
\text { Structured Sig recommends only SNOMED CT be used. } \\
\text { RECOMMENDATION: (1) Reconcile terminology } \\
\text { differences between the Observation and Structured Sig } \\
\text { statements and make adjustments to make them } \\
\text { consistent. (2) Make SCRIPT } 10.6 \text { and Structured Sig } 1.1 \\
\text { guidance consistent according to that outcome, to assist } \\
\text { implementers. }\end{array}$ \\
\hline
\end{tabular}

Adverse Reaction (The

SCRIPT Allergy segment is only in the Census message, which is in limited use in LTPAC settings only) 


\begin{tabular}{|c|c|c|c|}
\hline Concept & SCRIPT Terminology & $\begin{array}{c}\text { Compatibility } \\
\text { with C32 CCD } \\
\text { and CCR } \\
\end{array}$ & Challenges and Recommendations \\
\hline $\begin{array}{l}\text { Type of allergy or } \\
\text { adverse event }\end{array}$ & $\begin{array}{l}\text { Set of SNOMED CT values } \\
\text { defined in HITSP C } 80 \\
\text { Table 2-86 Allergy / } \\
\text { Adverse Event Type Value } \\
\text { Set Definition }\end{array}$ & $\begin{array}{l}\text { Terminology } \\
\text { consistent } \\
\text { between SCRIPT } \\
\text { and CCD. CCR } \\
\text { uses proprietary }\end{array}$ & No challenges or recommendations. \\
\hline $\begin{array}{l}\text { Medication } \\
\text { product }\end{array}$ & $\begin{array}{l}\text { RxNorm, representative } \\
\text { NDC11, UPC, or Mfr. } \\
\text { Code }\end{array}$ & $\begin{array}{l}\text { Roughly } \\
\text { consistent } \\
\text { terminology, with } \\
\text { SCRIPT } \\
\text { supporting } \\
\text { additional code } \\
\text { sets }\end{array}$ & $\begin{array}{l}\text { ISSUE: SCRIPT allows use of additional code sets not } \\
\text { used in other standards: representative NDC, } \\
\text { manufacturer code and UPC. } \\
\text { RECOMMENDATION: Because RxNorm is } \\
\text { recommended, consider eliminating support for } \\
\text { representative NDC, manufacturer code and UPC in this } \\
\text { element. }\end{array}$ \\
\hline Drug class & NDF-RT & $\begin{array}{l}\text { Roughly } \\
\text { consistent } \\
\text { terminology, but } \\
\text { different } \\
\text { constraints on } \\
\text { NDF-RT range }\end{array}$ & $\begin{array}{l}\text { ISSUE: NDF-RT is the recommended terminology for } \\
\text { this element in all reviewed standards. However, the } \\
\text { allowed set of NDF-RT codes is restricted further in the } \\
\text { C32 CCD than in the NCPDP or CCR standards. } \\
\text { RECOMMENDATION: Consider further constraining } \\
\text { the NDF-RT concepts allowed in SCRIPT to match those } \\
\text { allowed by the C32 CCD, to assist implementers with } \\
\text { both standards in their workflow. }\end{array}$ \\
\hline Food & UNII & $\begin{array}{l}\text { Roughly } \\
\text { consistent } \\
\text { terminology. }\end{array}$ & No challenges or recommendations. \\
\hline Reaction & $\begin{array}{l}\text { Values are a subset of those } \\
\text { defined in HITSP C } 80 \\
\text { (v2.01) 2.2.3.4.2 Allergy / } \\
\text { Adverse Event Type. } \\
\text { Specifically, only Clinical } \\
\text { Findings (concepts } \\
\text { descending from } \\
\text { 404684003) are allowed, } \\
\text { and not concepts } \\
\text { descending from Situation } \\
\text { with Explicit Context } \\
(243796009) \text {. }\end{array}$ & $\begin{array}{l}\text { Variance in } \\
\text { terminology due } \\
\text { to SCRIPT's use } \\
\text { of initial VA/KP } \\
\text { problem list } \\
\text { definition }\end{array}$ & $\begin{array}{l}\text { ISSUE: Both the C32 CCD and SCRIPT standards refer } \\
\text { to the VA/KP SNOMED CT Problem List Subset. } \\
\text { However, a variance has arisen due to a change to the } \\
\text { original HITSP specification, on which the SCRIPT } \\
\text { direction was based. } \\
\text { RECOMMENDATION: Consider updating SCRIPT's } \\
\text { ECL to reflect the current VA/KP SNOMED problem list } \\
\text { subset, benefitting implementers with both SCRIPT and } \\
\text { C32 CCD in the same workflow. }\end{array}$ \\
\hline
\end{tabular}




\begin{tabular}{|c|c|c|c|}
\hline Concept & SCRIPT Terminology & $\begin{array}{c}\text { Compatibility } \\
\text { with C32 CCD } \\
\text { and CCR } \\
\end{array}$ & Challenges and Recommendations \\
\hline Reaction Severity & $\begin{array}{l}\text { Values conform to HITSP } \\
\text { C80 2.2.3.1.6 Table 2-67 } \\
\text { Problem Severity set }\end{array}$ & $\begin{array}{l}\text { Consistent } \\
\text { terminology in } \\
\text { SCRIPT, C32. } \\
\text { CCR uses } \\
\text { proprietary }\end{array}$ & No challenges or recommendations. \\
\hline \multicolumn{4}{|c|}{$\begin{array}{l}\text { Problem (The SCRIPT } \\
\text { Diagnosis segment is only in the } \\
\text { Census message, which is in } \\
\text { limited use in LTPAC settings } \\
\text { only) }\end{array}$} \\
\hline Problem type & $\begin{array}{l}\text { Values conform to HITSP } \\
\text { C80 2.2.3.1.2 Table 2-60 } \\
\text { Problem Type Value Set } \\
\text { Definition }\end{array}$ & $\begin{array}{l}\text { Consistent } \\
\text { terminology in } \\
\text { SCRIPT, C32. } \\
\text { CCR uses } \\
\text { proprietary }\end{array}$ & No challenges or recommendations. \\
\hline Problem name & $\begin{array}{l}\text { Values are a subset of those } \\
\text { defined in HITSP C } 80 \\
\text { (v2.01) 2.2.3.1.1 Problem } \\
\text { Value Set. Specifically, } \\
\text { only Clinical Findings } \\
\text { (concepts descending from } \\
\text { 404684003) are allowed, } \\
\text { and not concepts } \\
\text { descending from Situation } \\
\text { with Explicit Context } \\
\text { (243796009). }\end{array}$ & $\begin{array}{l}\text { Variance in } \\
\text { terminology due } \\
\text { to SCRIPT's use } \\
\text { of initial VA/KP } \\
\text { problem list } \\
\text { definition }\end{array}$ & $\begin{array}{l}\text { ISSUE: Both the C32 CCD and SCRIPT standards refer } \\
\text { to the VA/KP SNOMED CT Problem List Subset. } \\
\text { However, a variance has arisen due to a change to the } \\
\text { original HITSP specification, on which the SCRIPT } \\
\text { direction was based. } \\
\text { RECOMMENDATION: Consider updating SCRIPT's } \\
\text { ECL to reflect the current VA/KP SNOMED problem list } \\
\text { subset, benefitting implementers with both SCRIPT and } \\
\text { C32 CCD in the same workflow. }\end{array}$ \\
\hline Problem status & Not supported by SCRIPT & $\begin{array}{l}\text { Not supported by } \\
\text { SCRIPT }\end{array}$ & $\begin{array}{l}\text { ISSUE: SCRIPT does not include a problem status } \\
\text { element. } \\
\text { RECOMMENDATION: Consider adding a problem } \\
\text { status element to the SCRIPT Diagnosis segment, using } \\
\text { terminology consistent with the C32 CCD (SNOMED } \\
\text { Code from C80 2.2.3.1.8 Table 2-70 Problem Status } \\
\text { Value Set Definition-active, inactive, resolved) }\end{array}$ \\
\hline
\end{tabular}

\section{A need for periodic terminology updates}

Certain of the element-level challenges in the summary above suggest a need for NCPDP to periodically review industry terminology usage - in order to keep SCRIPT consistent with other standards.

For example, the Diagnosis segment specifies a subset of SNOMED CT problems that matched the VA / Kaiser Permanente SNOMED problem list subset also used in the C32 CCD. However, over 
time, the definition of that problem list subset was amended in the C32 to include another set of SNOMED concepts. NCPDP did not likewise update its problem list definition, and as a result SCRIPT and the C32 CCD became out of sync.

RECOMMENDATION:

Based on this experience, it is recommended that NCPDP actively monitor the terminology used in standards with which it wishes SCRIPT to be consistent, and update its terminology use as needed. 


\section{Management of "External Code Lists"}

Terminology and other valid value sets used in the SCRIPT standard and other NCPDP standards are managed in a single "External Code List" (ECL) document. The ECL is updated independently of the SCRIPT standard as the elements requiring valid values or terminology are added to an NCPDP standard, industry conventions change, etc. Versions of the ECL are referred to using the date on which the version was published (e.g., "the April 2011 ECL").

NCPDP typically associates an "earliest" ECL version that can be used with a given SCRIPT version (in the case of 10.6, the earliest ECL to be used is from October 2008). Implementers are allowed to use code sets in that earliest ECL version or any ECL version up to the most recent, and the NCPDP Implementation of ePrescribing Standards document recommends use of the most recent ECL version.

While consolidating terminologies and values into a single document and management process has its benefits - especially where it is useful for the same terms to be used across NCPDP standards - there are real challenges associated with this approach as well. This section identifies certain of these challenges as they affect implementers of the SCRIPT standard.

Some challenges relate to the consolidation of terms and values from dissimilar standards (e.g., prescriptions and claims). Other challenges are the result of editorial conventions applied by NCPDP to the ECL document. And lastly, some challenges are related to the way that ECL concepts are integrated into the SCRIPT version 10.6 XML structure.

\section{Consolidation of terms and values from dissimilar standards}

In several instances, a single ECL code set is maintained to support a concept that is used (and often serves different purposes) in different message types. This results in cases where an element in a given SCRIPT message is allowed to convey values that are inappropriate in that context—values that are intended for use only in other message types.

RECOMMENDATION:

In the ECL, in cases where not all values for a concept are applicable in all composite / element instances where it appears, provide a separate set of code values for each instance containing only the applicable values. Update the XML schema accordingly.

Handling of concept changes with respect to actively-implemented standards A clinical or administrative concept used in the SCRIPT standard may "evolve" from its original definition over time due to corrections from within NCPDP or changes in external industry use of terminology. This evolution might take the form of more or fewer valid values, references to different standard terminologies, changes in constraints on standard terminologies, etc.

The way in which the ECL document is updated to reflect changes has a significant impact on implementers of an older version of SCRIPT (such as 10.6) that references such a changed concept.

In some cases, newer ECL versions apply those changes to the existing concept-enabling implementers of all SCRIPT versions use of the current values. This handling of changing concepts does not present a challenge for implementers - when they and their trading partners agree to use the newer ECL, the new value set replaces the old set for each 10.6 concept.

In other cases, however, the ECL omits content related to older versions of SCRIPT (including 10.6) in favor of content ostensibly limited to use in newer versions of the standard which are not yet allowed for use by federal programs. In these cases, NCPDP appears to have chosen to "replace" an existing concept with another that represents the same underlying domain of information. For 
example, the concept, 4343 Message Function, coded, which is present in version 10.6, is replaced in the current ECL version with a concept named MessageRequestCode.

The challenge for implementers arises when a 10.6 implementer references the current ECL version as directed by SCRIPT guidance, and they do not find certain concepts used in 10.6, such as 4343 Message Function, coded noted above. Instead, upon searching the text of the ECL document they will find the statement, "See 4343 Message Function, coded for SCRIPT Versions $1 \varnothing .11$ and lower". Upon further searching, however, the implementer will learn that the current ECL does not contain a definition for the referenced concept (4343 Message Function, coded).

RECOMMENDATION:

Implementers would benefit from a consistent editorial policy to include all concepts included in actively-implemented SCRIPT versions, cross-referencing as applicable to replacement concepts or version-constrained values as applicable.

Including all version 10.6 ECL concepts in current ECL document versions will enable an implementer to use a single ECL version rather than needing to "mix and match" versions in order to cover all 10.6 concepts. This will also reduce confusion for implementers who reasonably expect the current ECL version to cover all concepts included in the most recent SCRIPT version in use in the industry and named in federal regulation. 


\section{Other Implementability}

This section identifies other challenges presented by the SCRIPT 10.6 standard from the perspective of the implementer, describing how the components of the standard fit together from an implementer's perspective, assessing strengths and weaknesses and calling out opportunities for improvement. While findings from the quality and terminology reviews factor into this assessment, this section focuses on management of changes to the standard and documents related to it, including identification of errors and errata in documentation, capturing of additional guidance in response to implementer questions and experience, and synchronization of XML schema content with the NCPDP External Code List (ECL).

\section{Maintenance of up-to-date implementation materials for those integrating the SCRIPT 10.6 version into their systems}

One challenge for implementers is that an error, omission, or weakness of a given SCRIPT version is typically addressed by NCPDP in a later version of the standard - but is not corrected in the specification or implementation materials of the version containing the issue. Because SCRIPT 10.6 was created in 2008, several SCRIPT versions have followed it, and several of its weaknesses have been addressed in this manner, with resolutions in later versions.

For the implementer of 10.6, these recent-version corrections are of little use; the implementer remains limited to the specification and implementation materials of the 10.6 standard. NCPDP does not have a policy of capturing a version's errors or issues in a way that can be distributed with the version itself, to highlight these challenges or to provide clarifications or work-arounds for implementers. Instead, the implementer must look to newer versions of the standard and apply its improved guidance — where applicable — back to 10.6. RECOMMENDATION:

It would be beneficial to implementers for NCPDP to have a program by which implementation experience is captured and made available in conjunction with the standard it applies to, in an addendum to the standard, errata, and/or other forms. Such a process would be a means for gaining industry consensus on clarifications to unclear or under-specified aspects of SCRIPT 10.6 or other versions, and capturing them to prevent the need for individual implementers and trading partners to arrive at them separately (potentially with different outcomes).

\section{ECL Version Management and the XML Schema}

The structure of the version 10.6 XML is such that external code list values are "baked in" to the schema. As such, the schema reflects the External Code List at a particular point in time (if one version of the ECL is integrated in its entirety) or a particular mix of External Code List concepts (if the schema contains values from more than one ECL version, which is the case today). NCPDP has typically not updated the 10.6 schema with each update to the ECL, but instead has made adjustments as requested by implementers... for example, adding the RxNorm coded drug values as required by federal Meaningful Use rules.

A challenge presented by this situation is that, if an implementer wishes to use an ECL version that differs from what has been integrated into the XML schema, they must manually update values throughout the schema - a process prone to error. Further, the fact that the 10.6 schema does not typically include the most recent ECL version contrasts the direction given in the NCPDP Implementation of ePrescribing Standards document (201009.Read.me.eprescribing.pdf), which states that the most recent ECL is recommended. 
The XML structure in later versions of SCRIPT separates the ECL values from the rest of the message content, partially addressing these challenges. However, that structural change does not address inconsistency in NCPDP guidance regarding the preferred ECL version.

RECOMMENDATION:

Implementers would benefit from clear and consistent guidance from NCPDP on the preferred ECL version to be implemented, and for that version to be reflected in the SCRIPT 10.6 XML schema, with updates to the schema made with each ECL version.

Further, direction regarding the use of value sets from multiple ECL versions in a given 10.6 implementation would be helpful towards consistency between vendors. 
The following NCPDP documentation associated with SCRIPT 10.6 is referenced in this assessment.

- SCRIPT 10.6 Implementation Guide, October 2008. (Approval Date for ANSI: November 12, 2008)

- Data Dictionary, October 2008

- NCPDP Standards Matrix

- SCRIPT Implementation Recommendations, Version 10.6 (April, 2011)

- Implementation of ePrescribing Standards "read me" document (201009.read.me.eprescribing.pdf)

- ECL versions October, 2008 (earliest for use with SCRIPT 10.6) and a current ECL during the course of this assessment (April, 2011)

- Structured Sig version 1.1 Implementation Guide

- SCRIPT XML Standard, version 2010121. (Approval Date for ANSI: January 28, 2011) Source of Trace Number Usage content recommended as guidance for SCRIPT 10.6 implementers. 